\title{
Inhibition of 11ß-hydroxysteroid dehydrogenase 2 by the fungicides itraconazole and posaconazole
}

Katharina R. Beck ${ }^{1}$, Murielle Bächler ${ }^{1}$, Anna Vuorinen ${ }^{1}$, Sandra Wagner ${ }^{2}$, Muhammad Akram², Ulrich Griesser ${ }^{3}$, Veronika Temml ${ }^{2}$, Petra Klusonova ${ }^{1}$, Hideaki Yamaguchi ${ }^{4}$, Daniela Schuster ${ }^{2}$, Alex Odermatt ${ }^{1 *}$

${ }^{1}$ Swiss Center for Applied Human Toxicology and Division of Molecular and Systems Toxicology, Department of Pharmaceutical Sciences, Pharmazentrum, University of Basel, Klingelbergstrasse 50, 4056 Basel, Switzerland. KRB: katharina.beck@unibas.ch; MB: murielle.baechler@stud.unibas.ch; $\quad$ AV: $\quad$ anna.vuorinen1 @gmail.com; $\quad$ PK: petra.klusonova@unibas.ch; AO: $\underline{\text { alex.odermatt@unibas.ch. }}$

${ }^{2}$ Institute of Pharmacy/Pharmaceutical Chemistry and Center for Molecular Biosciences Innsbruck (CMBI), Computer Aided Molecular Design Group, University of Innsbruck, Innrain 80/82, 6020 Innsbruck, Austria. SW: sandra.wagner@student.uibk.ac.at; MA: muhammad.akram@uibk.ac.at; $\quad$ VT: $\quad$ veronika.temml@uibk.ac.at; $\quad$ DS: daniela.schuster@uibk.ac.at.

${ }^{3}$ Institute of Pharmacy/Pharmaceutical Technology, University of Innsbruck, Innrain 80/82, 6020 Innsbruck, Austria. UG: ulrich.griesser@uibk.ac.at.

${ }^{4}$ Department of Applied Biological Chemistry, Meijo University, Nagoya 468-8502, Japan. HY: hyamagu@meijo-u.ac.jp.

*Address of correspondence: Prof. Dr. Alex Odermatt, Swiss Center for Applied Human Toxicology and Division of Molecular and Systems Toxicology, Department of Pharmaceutical Sciences, University of Basel, Klingelbergstrasse 50, 4056 Basel, Switzerland Alex.Odermatt@unibas.ch; Phone: + 416120715 30; Fax: + 41612071515 


\begin{abstract}

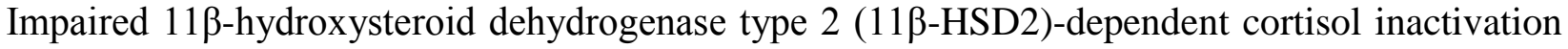
can lead to electrolyte dysbalance, hypertension and cardiometabolic disease. Furthermore, placental $11 \beta$-HSD2 essentially protects the fetus from high maternal glucocorticoid levels, and its impaired function has been associated with altered fetal growth and a higher risk for cardiometabolic diseases in later life. Despite its important role, $11 \beta-$ HSD2 is not included in current off-target screening approaches. To identify potential $11 \beta$-HSD inhibitors amongst approved drugs, a pharmacophore model was used for virtual screening, followed by biological assessment of selected hits. This led to the identification of several azole fungicides as 11 $\beta$-HSD inhibitors, showing a significant structure-activity relationship between azole scaffold size, 11 $\beta$-HSD enzyme selectivity and inhibitory potency. A hydrophobic linker connecting the azole ring to the other, more polar end of the molecule was observed to be favorable for 11 $\beta$-HSD2 inhibition and selectivity over $11 \beta$-HSD1. The most potent $11 \beta$-HSD2 inhibition, using cell lysates expressing recombinant human $11 \beta$-HSD2, was obtained for itraconazole $\left(\mathrm{IC}_{50} 139 \pm 14 \mathrm{nM}\right)$, its active metabolite hydroxyitraconazole $\left(\mathrm{IC}_{50} 223 \pm 31 \mathrm{nM}\right)$ and posaconazole $\left(\mathrm{IC}_{50} 460 \pm 98 \mathrm{nM}\right)$. Interestingly, experiments with mouse and rat kidney homogenates showed considerably lower inhibitory activity of these compounds toward 11ß-HSD2, indicating important species-specific differences. Thus, $11 \beta$-HSD2 inhibition by these compounds are likely to be overlooked in preclinical rodent studies. Inhibition of placental $11 \beta-\mathrm{HSD} 2$ by these compounds, in addition to the known inhibition of cytochrome P450 enzymes and P-glycoprotein efflux transport, might contribute to elevated local cortisol levels, thereby affecting fetal programming.
\end{abstract}

\title{
Keywords
}

11 $\beta$-hydroxysteroid dehydrogenase, virtual screening, reproductive toxicity, itraconazole, posaconazole, glucocorticoid 


\title{
Chemical compounds studied in this article
}

\begin{abstract}
Albendazole (PubChem CID: 2082); Butaconazole (PubChem CID: 47472); Climbazole (PubChem CID: 37907); Itraconazole (PubChem CID: 55283); Hydroxyitraconazole (PubChem CID: 108222); Ketoconazole (PubChem CID: 47576); Posaconazole (PubChem CID: 468595); Sertaconazole (PubChem CID: 65863); Terconazole (PubChem CID: 441383); Tioconazole (PubChem CID: 5482)
\end{abstract}

\begin{abstract}
Abbreviations

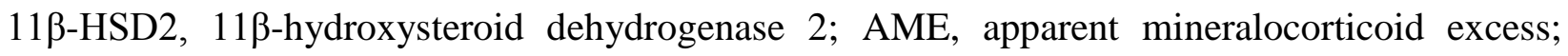
androstenedione, $\Delta 4$-androstene-3,17-dione; $\mathrm{CRH}$, corticotrophin releasing hormone; DHEA, dehydroepiandrosterone; DHT, 5 $\alpha$-dihydrotestosterone; DMEM, Dulbecco's modified Eagle medium; GR, glucocorticoid receptor; H6PDH, hexose-6-phosphate dehydrogenase; HEK-293, Human Embryonic Kidney-293 cells; HPA, hypothalamic-pituitary-adrenal; MR, mineralocorticoid receptor; OHI, hydroxyitraconazole; P-gp, P-glycoprotein; TLC, thin layer chromatography; VS, virtual screening.
\end{abstract}




\section{Introduction}

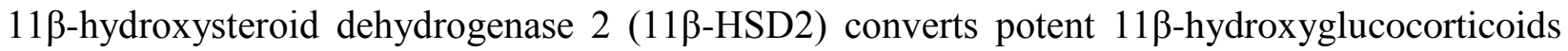
(cortisol, corticosterone) into their inactive 11-keto forms (cortisone, 11-dehydrocorticosterone), thereby controlling tissue-specific activities of mineralocorticoid receptors (MR) and glucocorticoid receptors (GR) [1]. 11ß-HSD2 is essentially involved in the regulation of electrolyte balance, vascular function, and angiogenesis, as well as in the fetal-placental barrier to inactivate cortisol and protect the fetus from high maternal glucocorticoid levels [2, 3].

The consequences of impaired 11 $\beta$-HSD2 function are manifested in patients with genetic lossof-function mutations suffering from apparent mineralocorticoid excess (AME) $[2,4,5]$. In these patients the excessive cortisol-dependent MR activation in the kidney and colon results in hypokalemia, hypernatremia and water retention, leading to severe hypertension characterized by low renin, low aldosterone and increased plasma and urinary cortisol to cortisone ratios. $11 \beta$ HSD2 activity is essential since very early on in life, because birth weights of individuals homozygous/compound heterozygous for $H S D 11 B 2$ mutations were found to be significantly lower than those of their unaffected siblings [6]. Milder acquired forms of AME can be caused by inhibition of $11 \beta$-HSD2, for instance upon consumption of considerable amounts of licorice, containing the potent $11 \beta$-HSD inhibitor glycyrrhetinic acid (GA) [7].

The exposure to $11 \beta$-HSD2 inhibitors is especially critical during pregnancy. 11 -HSD2 builds a placental barrier by protecting the fetus from the 5-10 times higher maternal glucocorticoid levels in the course of a normal pregnancy [8-11]. Nevertheless, this barrier is not entirely complete, as a minor proportion of maternal cortisol is able to cross the placenta [11]. Glucocorticoids are important mediators of fetal growth, development and organ maturation. Rising total plasma cortisol levels during pregnancy, peaking in the third trimester at three-fold non-pregnant levels [12], are in parallel with progressive maturation of fetal organs, most notably the stimulation of 
surfactant production by the lung. However, glucocorticoid administration, especially during late gestation, has been associated with reduced birth weight, elevated blood pressure, higher insulin, increased distractibility and attention deficit later in life [13-17]. The correlation between low birth weight, albeit in normal ranges, and subsequent diseases in adulthood was found to be largely independent of confounding life style factors such as smoking or obesity [15]. It has been hypothesized that a reduced placental $11 \beta$-HSD2 activity is responsible for the high glucocorticoid concentrations reaching the fetus and subsequent programming of disease susceptibility [18]. Importantly, low 11ß-HSD2 expression was found to be associated with intrauterine growth restriction pregnancies in humans and in rodent models [19-22]. Determination of osteocalcin concentration in human cord blood samples, which is a sensitive marker of glucocorticoid exposure in adult humans, revealed a direct correlation with placental $11 \beta$-HSD2 activity [23].

Treatment of pregnant rats with dexamethasone, which cannot be inactivated by 11ß-HSD2 [24], led to lower birth weights and caused HPA axis hyperactivity, hypertension, hyperglycemia and increased anxiety behavior [20, 25]. Similarly, administration of the unselective 11 $\beta$-HSD inhibitor carbenoxolone to pregnant rats resulted in reduced birth weight, and adult offspring showed enhanced HPA activity with increased glucocorticoid and CRH levels as well as elevated blood pressure $[26,27]$. Evidence for the importance of placental $11 \beta$-HSD2 was contributed by studies with placentas from $11 \beta$-HSD2-deficient mice showing increased amino acid and reduced glucose transport as well as lower expression levels of genes important for angiogenesis [28]. Furthermore, maternal stress and malnutrition in rats were reported to be able to down regulate placental 11 $\beta$-HSD2 and program for diseases in adult life [29-31]. Factors including sex steroids, nitric oxide, prostaglandins, proinflammatory cytokines, infections and environmental 
pollutants were shown to have the potential to reduce $11 \beta-\mathrm{HSD} 2$ activity in studies using placental cell lines [32, 33].

Observational studies showed that pregnant Finnish women consuming large amounts of licorice (containing the unselective 11ß-HSD inhibitor glycyrrhetinic acid) had shorter gestation times [34] and gave birth to children with behavioral disturbances and poorer cognitive functions coupled with increased HPA axis activity, in a dose-dependent manner [35, 36]. Compromised $11 \beta-H S D 2$ function during pregnancy has also been implicated in preeclampsia, a major cause of maternal and perinatal mortality; however, the etiology is poorly understood [37, 38].

Due to its important physiological role and the adverse effects observed upon its inhibition, 11ßHSD2 can be considered as an anti-target for drug development (with a few specific exceptions where these effects are wanted); however, it is not included in current off-target screening approaches. The present study addressed possible inhibitory effects of approved drugs toward $11 \beta$-HSD2 by performing a virtual screening (VS) of the DrugBank database using an $11 \beta-\mathrm{HSD}$ pharmacophore model. This was followed by a biological evaluation of selected hits, with a focus on the azole fungicides itraconazole and posaconazole.

\section{Materials and methods}

\subsection{Chemicals and reagents}

$\left[1,2,6,7-{ }^{3} \mathrm{H}\right]$-cortisol, $\left[2,4,6,7-{ }^{3} \mathrm{H}\right]$-estrone and $\left[2,4,6,7-{ }^{3} \mathrm{H}\right]$-estradiol were purchased from PerkinElmer (Boston, MA, USA), $\left[1,2-{ }^{3} \mathrm{H}\right]$-cortisone from American Radiolabeled Chemicals (St. Louis, MO), hydroxyitraconazole (OHI) from Carbosynth (Berkshire, UK) and all other chemicals from Sigma Aldrich (Buchs, Switzerland) of the highest grade available. Cell culture media were obtained from Sigma Aldrich (Buchs, Switzerland). 


\section{2. $\quad$ Pharmacophore modeling and virtual screening}

The 11ß-HSD inhibitor pharmacophore model used for this study was previously reported and validated [39]. The model was initially based on three potent, structurally diverse $11 \beta-H S D$ inhibitors [40] and refined with recent literature and novel screening data (model 4new in reference [39], Fig. 1A).

To discover potential 11ß-HSD inhibitors amongst FDA-approved drugs and nutraceuticals, the DrugBank version 3.0 was downloaded as sd file (1543 approved drugs and 84 nutraceuticals) and transformed into a 3D-multiconformational database using the "build database" protocol of Discovery Studio 4.0 (Discovery Studio, Version 4.0, Biovia Inc., San Diego, CA, 2014). For each compound, a maximum of 255 conformers was calculated using fast settings. For the VS, the "search 3D database" protocol with BEST flexible search was used. The DrugBank database was screened with the 11ß-HSD inhibitors model using Discovery Studio 4.0.

\subsection{Cell culture}

Human Embryonic Kidney-293 cells (HEK-293) cells (used at passage number 15-30), human SW-620 colon carcinoma cells (passage number 11-15) and human MCF-7 breast cancer cells (passage number 19-27) were obtained from ATCC (Manassas, VA, USA) and were cultured in Dulbecco's modified Eagle medium (DMEM) supplemented with 10\% fetal bovine serum, 4.5 g/L glucose, 100U/mL penicillin/streptomycin, 2 mM L-glutamine, $10 \mathrm{mM}$ HEPES, pH 7.4, and 10\% MEM non-essential amino acid solution.

\subsection{Determination of $11 \beta$-HSD activity in cell lysates}

Enzyme activities were determined as described earlier using lysates of HEK-293 cells stably expressing human 11ß-HSD1 and hexose-6-phosphate dehydrogenase (H6PDH; HHH7 clone) or 


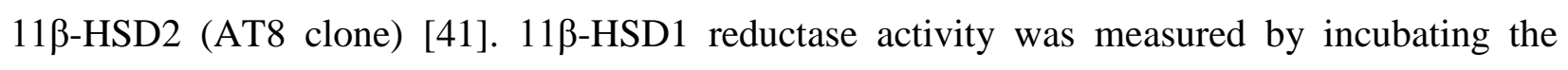
lysates for $10 \mathrm{~min}$ at $37^{\circ} \mathrm{C}$ in a total volume of $22 \mu \mathrm{L}$ containing $200 \mathrm{nM}$ radiolabeled cortisone, $500 \mu \mathrm{M}$ NADPH and test substance or vehicle (DMSO at a maximal concentration of $0.1 \%$ ). $11 \beta$-HSD2-dependent oxidation was assessed in the presence of $200 \mathrm{nM}$ radiolabeled cortisol and $500 \mu \mathrm{M} \mathrm{NAD}{ }^{+}$. The reactions were stopped by adding an excess amount of unlabeled cortisone and cortisol (1:1, $2 \mathrm{mM}$ in methanol). Approximately $20-25 \%$ of the substrate were converted to the corresponding product. Steroids were separated by thin layer chromatography (TLC) using chloroform and methanol (9:1). Conversion of radiolabeled substrate was measured by scintillation counting. The substrate conversion was determined and compared to the enzyme activity in the control sample.

To exclude irreversible 11 $\beta$-HSD2 inhibition by the investigated compounds, HEK cell lysates were preincubated with the corresponding compounds for 0,5 and 20 min at $4{ }^{\circ} \mathrm{C}$, followed by determination of enzyme activity. Alternatively, lysate were preincubated with the compounds for 10 min followed by subsequent dilution (1:2 or $1: 4)$ and determination of enzyme activity [42]. Data (mean \pm SD) were normalized to vehicle control (DMSO) and obtained from at least three independent experiments.

\subsection{Determination of $11 \beta$-HSD2 activity in intact cells}

$11 \beta-\mathrm{HSD} 2$ activity measurement in intact SW-620 and MCF-7 cells was determined as described earlier [43]. Briefly, 100000 SW-620 and 50000 MCF-7 cells per well were seeded in 96-well plates. The medium was replaced after 24 h by $40 \mu \mathrm{L}$ steroid- and serum-free DMEM (DMEMsf) containing either vehicle or inhibitor and $10 \mu \mathrm{L}$ medium containing $10 \mathrm{nCi}$ radiolabeled cortisol and unlabeled cortisol to reach a final concentration of $50 \mathrm{nM}$. SW-620 cells were incubated for 4 
$\mathrm{h}$ and MCF-7 cells for $5 \mathrm{~h}$ at $37^{\circ} \mathrm{C}$, followed by analysis of steroid conversion by TLC and scintillation counting

\subsection{Determination of $17 \beta-H S D 1$ and $17 \beta-H S D 2$ activity in cell lysates}

Determination of $17 \beta-H S D 1$ and $17 \beta-H S D 2$ activity was conducted as described earlier [44].

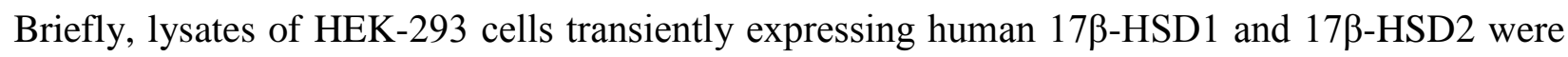
incubated for $10 \mathrm{~min}$ at $37^{\circ} \mathrm{C}$ in a total volume of $22 \mu \mathrm{L}$ in the presence $200 \mathrm{nM}$ estrone containing $50 \mathrm{nCi}$ of $\left[2,4,6,7-{ }^{3} \mathrm{H}\right]$-estrone and $500 \mu \mathrm{M}$ NAPDH for $17 \beta$-HSD1, and with $200 \mathrm{nM}$ estradiol containing $50 \mathrm{nCi}$ of $\left[2,4,6,7-{ }^{3} \mathrm{H}\right]$-estradiol and $500 \mu \mathrm{M} \mathrm{NAD}{ }^{+}$for $17 \beta-\mathrm{HSD} 2$ activity measurements. Steroids were separated using TLC and substrate conversion determined by scintillation counting. Data (mean \pm SD) were normalized to vehicle control (DMSO) and obtained from at least three independent experiments.

\subsection{Determination of $11 \beta$-HSD activity in mouse and rat kidney homogenates}

Mouse (C57BL6) and rat (Wistar) kidney tissue from adult males were snap frozen in liquid nitrogen and stored at $-80^{\circ} \mathrm{C}$ until further use. For homogenate preparation, frozen tissue was sonicated in homogenization buffer $(250 \mathrm{mM}$ sucrose, $10 \mathrm{mM}$ HEPES, $\mathrm{pH} 7.4$; $900 \mu \mathrm{L}$ for $100 \mathrm{mg}$ of kidney) and centrifuged at $2000 \times \mathrm{g}, 4^{\circ} \mathrm{C}$ for $10 \mathrm{~min}$ to remove cell debris. The total protein concentration was determined by BCA assay [45]. The homogenates were prediluted to a protein concentration of $3.75 \mathrm{mg}$ of protein $/ \mathrm{mL}$ (mouse) or $10 \mathrm{mg}$ of protein $/ \mathrm{mL}$ (rat) in homogenization buffer. Reactions were performed in a total volume of $22 \mu \mathrm{L}$ incubation buffer (300 mM NaCl, 20 mM Tris(hydroxymethyl)aminomethane-hydrocholoride, $1 \mathrm{mM}$ EDTA, 10\% glycerol, $\mathrm{pH} 7.7$ ) containing $0.075 \mathrm{mg} / \mathrm{mL}$ of mouse and $0.2 \mathrm{mg} / \mathrm{mL}$ of rat total kidney protein, respectively, as well as $10 \mu \mathrm{M}$ of test compound, $50 \mathrm{nM}$ of corticosterone (containing $50 \mathrm{nCi}$ 
$\left[1,2,6,7-{ }^{3} \mathrm{H}\right]$ corticosterone) and $500 \mu \mathrm{M} \mathrm{NAD}^{+}$at $37^{\circ} \mathrm{C}$ for $20 \mathrm{~min}$. Approximately $20-25 \%$ of the substrate were converted. The steroids were separated by TLC and conversion of radiolabeled substrate was measured by scintillation counting.

\subsection{Docking}

Docking was performed using GOLD 5.2 (The Cambridge Crystallographic Data Centre, Cambridge, UK, [46]) based on a crystal structure of 11ß-HSD1 (co-crystallized with (2R)-4-[4fluoro-2-(trifluoromethyl)phenyl]-2-methyl-1-([3-(1H-1,2,4-triazol-1yl)phenyl]sulfonyl)piperazine, PDB code 3HFG [47]) and a homology model for human $11 \beta$ HSD2 [48] and murine 11ß-HSD2 [49]. The PDB entry 3HFG was chosen for two reasons. First, it was the template for generating the homology model of human and murine 11 $\beta$-HSD2. Second, the co-crystallized inhibitor is of similar size as some of the investigated antifungals and contains a triazole moiety. It therefore probably constitutes a binding site conformation suitable for docking this class of $11 \beta$-HSD1 inhibitors.

The ligand binding pocket was defined as a sphere with a $10 \AA$ radius around the coordinates $\mathrm{X}=$ $-19.50 \mathrm{Y}=4.00, \mathrm{Z}=14.25$. ChemPLP was used as scoring function. As workflow validation, redocking of the original ligand was performed using default settings and the best ranked pose deviates from the crystal structure with an RMSD of 0.856 for $11 \beta-H S D 1$. As both the homology models for human and murine $11 \beta$-HSD2 were initially based on PDB entry $3 \mathrm{HFG}$, the same coordinates were used to define the binding site for this docking. For human 11/-HSD2, the docking was additionally repeated setting Arg212 as flexible amino acid. The binding poses were analyzed using LigandScout 4.1 [50] (Inte:Ligand GmbH, Vienna, Austria).

\section{Results}




\subsection{Virtual screening of the DrugBank database using a 11B-HSD pharmacophore model and}

virtual hit selection for biological evaluation

Despite its role in the regulation of electrolyte balance and cardiovascular function and its importance during pregnancy to control the in utero environment and therefore fetal growth and development, 11ß-HSD2 is not included in current drug off-target screenings. Thus, the present project aimed to evaluate some approved drugs for their ability to interfere with $11 \beta-\mathrm{HSD} 2$ activity. For this purpose, the FDA-approved small molecule drug entries of the DrugBank database were subjected to VS using a previously developed $11 \beta$-HSD pharmacophore model (Fig. 1A) [39]. This model is not expected to discriminate between $11 \beta-H S D 1$ and $11 \beta-H S D 2$ inhibitors because no crystal structure is available for $11 \beta-\mathrm{HSD} 2$ and the model is, at least in part, built based on available 11ß-HSD1 ligands. Of the 1543 DrugBank entries, 101 approved drugs fitted into the model. Not surprisingly, several steroidal compounds (in total 18 hits) including mainly glucocorticoids, were among the hits. Besides, the virtual hit list contained several prostaglandin analogues as well as anti-infective agents, including antifungals, antibiotics and antiparasitic agents. Antifungals were especially represented by the class of azole fungicides, with sertaconazole, butoconazole and tioconazole as virtual hits (Fig. 1B). The majority of antibiotics comprised $\beta$-lactam antibiotics and lincosamides, with cloxacillin, flucloxacillin and nafcillin, as well as clindamycin and lyncomycin as representative structural classes. Further virtual hits included members of the classes of antihypertensives/antiarrhythmics, diuretics, lipid lowering drugs, antidiabetics, analgesics and antipsychotics. Several hits from the VS, belonging to the different structural classes mentioned above and available through an in-house chemical repository, were selected for biological assessment. 


\subsection{Effect of selected virtual hits and further structurally related compounds on 11 $\beta$-HSD activity}

The selected compounds were first tested for their potential to inhibit cortisol to cortisone conversion in lysates of HEK-293 cells stably expressing human 11ß-HSD2. The selectivity over the closely related $11 \beta$-HSD1 was then determined by measuring the effect of the chemicals on the conversion of cortisone to cortisol. The selected steroids (nandrolone), antiarrhythmics (amiodarone), lipid lowering drugs (atorvastatin, simvastatin), diabetics (rosiglitazone), diuretics (ethacrynic acid), analgesics (indomethacine, nabilone), antipsychotics/sedativa (chlorpromazine), the uricosuric probenecid, antiparasitic agents (amodiaquine, chloroquine and pentamidine), $\beta$-lactam antibiotics (cloxacillin, flucloxacillin and nafcillin), lincosamides (clindamycin and lincomycin) and the steroid-like antibiotic fusidic acid showed no or weak inhibition (less than $40 \%$ inhibition) of $11 \beta-\mathrm{HSD} 1$ and $11 \beta-\mathrm{HSD} 2$ enzyme activity at a concentration of $20 \mu \mathrm{M}$ (data not shown). However, the azole fungicides sertaconazole, butoconazole and tioconazole showed moderate activity and inhibited 11ß-HSD2 at a concentration of $20 \mu \mathrm{M}$, resulting in $61 \%, 44 \%$ and $50 \%$ residual activity, respectively. These azole fungicides were not selective, and they equally well or preferentially inhibited 11ß-HSD1, showing residual enzyme activities of $35 \%, 48 \%$ and $18 \%$, respectively.

Due to their wide use and partial over-the-counter availability, and their previous association with $11 \beta-H S D s$ (triadimefon as a substrate of $11 \beta-H S D 1$ and ketoconazole as a weak inhibitor of $11 \beta$ HSD1 and 11 -HSD2 [39, 51]), additional, structurally related azole fungicides were selected for biological testing in order to provide proof of concept in applying pharmacophores as initial filter for the identification of hazardous compound classes [52]. The biological analyses using HEK293 cell lysates expressing recombinant human enzymes revealed a clear structure-activity relationship between $11 \beta$-HSD selectivity and structural size and shape of the azoles: the larger 


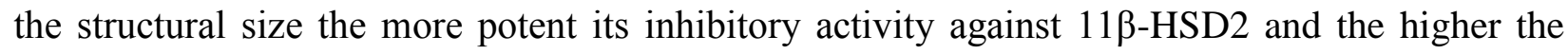
selectivity over 11ß-HSD1 (Fig. 2). One requirement of high activity was a hydrophobic central region of the azole scaffold linked to a more polar end. The compounds with a smaller scaffold preferentially inhibited $11 \beta-H S D 1$. In addition, the subdivision of azoles in imidazole and triazole derivatives revealed a further relationship. Imidazoles such as tioconazole, sertaconazole and butoconazole preferably inhibited $11 \beta$-HSD1 over $11 \beta$-HSD2, whereas triazoles such as terconazole, posaconazole and itraconazole more potently inhibited 11 $\beta$-HSD2. Albendazole, possessing a small azole scaffold containing a benzimidazol structure, was inactive against both enzymes. The most potent $11 \beta-\mathrm{HSD} 2$ inhibition was found for itraconazole and posaconazole, with $\mathrm{IC}_{50}$ values of $139 \pm 14 \mathrm{nM}$ and $460 \pm 98 \mathrm{nM}$ (Fig. 3), respectively, and selectivity over $11 \beta-$ HSD1 (Fig. 2). Furthermore, as itraconazole is mainly metabolized to the pharmacologically active $\mathrm{OHI}$, this metabolite was also tested, yielding an $\mathrm{IC}_{50}$ value of $223 \pm 31 \mathrm{nM}$ against $11 \beta$ HSD2. Irreversible 11 $\beta$-HSD2 inhibition by itraconazole, OHI and posaconazole was excluded by preincubation experiments; however, preincubation did not alter the inhibitory effect, suggesting a competitive mode of inhibition in line with competition for substrate binding.

\subsection{Selectivity assessment of the azole fungicides over $17 \beta$-HSD1 and $17 \beta-H S D 2$}

Although $11 \beta-\mathrm{HSD} 2$ and $11 \beta-\mathrm{HSD} 1$ are responsible for the interconversion of the same substrate, i.e. glucocorticoids, they are distant homologs sharing only about $18 \%$ sequence identity [53]. In contrast, human $17 \beta-\mathrm{HSD} 2$ is more closely related to $11 \beta$-HSD2 with about $45 \%$ amino acid sequence identity. $17 \beta-\mathrm{HSD} 2$ is predominantly involved in the metabolism of sex steroid hormones, inactivating estradiol to estrone, testosterone into $\Delta 4$-androstene-3,17-dione (androstenedione), 5 $\alpha$-dihydrotestosterone (DHT) into $5 \alpha$-androstanedione or 5-androstene$3 \beta, 17 \beta$-diol to dehydroepiandrosterone (DHEA). The reverse reaction of activating the weak 
estrogen estrone to the potent estradiol and to a minor extent DHEA to 5 -androstene-3 $\beta, 17 \beta$-diol is catalyzed by $17 \beta-\mathrm{HSD} 1$. Due to the high expression of $17 \beta-\mathrm{HSD} 1$ and $17 \beta-\mathrm{HSD} 2$ in placenta $[54,55]$, itraconazole, $\mathrm{OHI}$ and posaconazole were assessed for their potential to inhibit $17 \beta-$ HSD1 and 17ß-HSD2 enzyme activity in lysates of HEK-293 cells transiently expressing human $17 \beta-H S D 1$ and $17 \beta-H S D 2$. None of the compounds inhibited $17 \beta-H S D 1$ or $17 \beta-H S D 2$ activity (data not shown).

\subsection{Species-specific 11 $\beta$-HSD2 inhibition by the selected azole fungicides}

Earlier studies emphasized the importance to assess species-specific differences of $11 \beta$-HSD1 and $11 \beta-H S D 2$ inhibitors, especially prior to conducting in vivo experiments $[43,51,56]$. Thus, prior to designing a rodent study to assess the effect of the selected azole fungicides on glucocorticoid inactivation, inhibition of $11 \beta$-HSD2 by itraconazole, $\mathrm{OHI}$ and posaconazole was further analyzed in rat and mouse kidney homogenates incubated with $50 \mathrm{nM}$ of the rodent substrate corticosterone in the absence or presence of $10 \mu \mathrm{M}$ test compound. In a qualitative comparison to the potent activity against recombinant human $11 \beta-\mathrm{HSD} 2$, which was expressed in HEK-293 cells and measured upon incubation with $200 \mathrm{nM}$ of the human substrate cortisol, considerably lower inhibitory activity was detected against the rat and mouse enzymes. The different concentrations of corticosterone and cortisol used for rodent and human 11ß-HSD2, respectively, reflect the approximately 5-10 fold affinity difference for these substrates $[57,58]$. Itraconazole (Fig. 4A) and OHI (Fig. 4B) were at least 10 -fold less potent toward rat and mouse 11 $\beta$-HSD2 compared to the human enzyme, while posaconazole (Fig. 4C) tended to be 2 times less active against rat $11 \beta-\mathrm{HSD} 2$ and was about 4 times less active against mouse $11 \beta-\mathrm{HSD} 2$. Although the activities of the human and rodent enzymes were measured under different conditions, considering their different physiological substrates, the data suggest a higher 
inhibitory activity of these azole fungicides toward human 11 -HSD2 compared to the rodent enzymes.

\subsection{Inhibition of 11 $\quad$-HSD2 in cell models with endogenous enzyme expression}

To determine the inhibitory potential of itraconazole, OHI and posaconazole in intact cell systems, SW-620 and MCF-7 cells expressing relatively high endogenous 11ß-HSD2 levels [43] were applied. Itraconazole inhibited $11 \beta-\mathrm{HSD} 2$ in a concentration-dependent manner with $\mathrm{IC}_{50}$ values of $1.07 \pm 0.29 \mu \mathrm{M}$ in SW-620 and $1.19 \pm 0.24 \mu \mathrm{M}$ in MCF-7 cells. In contrast to the inhibitory potency ranking observed in lysates of stably transfected HEK-293 cells, OHI was slightly more potent than itraconazole with $\mathrm{IC}_{50}$ values of $0.82 \pm 0.18 \mu \mathrm{M}$ in SW-620 and $0.68 \pm$ $0.20 \mu \mathrm{M}$ in MCF-7 cells, respectively. Posaconazole did not substantially inhibit 11 $\beta$-HSD2 activity, resulting in approximately $60 \%$ and $40 \%$ residual $11 \beta-\mathrm{HSD} 2$ activity in SW-620 and MCF-7 cells at a concentration of $5 \mu \mathrm{M}$.

\section{6. $\quad$ Predicted binding of selected fungicides to $11 \beta$-HSD1 and $11 \beta$-HSD2}

Docking studies with $11 \beta$-HSD1 showed two important protein-ligand interactions for azole fungicides such as sertaconazole and tioconazole: a hydrophobic contact with Tyr183 and a hydrogen bond of the azole ring with the backbone nitrogen of Ala172 (Fig. 5A). This hydrogen bond interaction was also the only ligand-coordinating hydrogen bond observed in the 11 $\beta$-HSD1 crystal structure co-crystallized with a sulfonyl-piperazine inhibitor and thus, presumably essential for the inhibitory activity. In contrast, terconazole does not form any hydrogen bonds with the binding pocket of $11 \beta$-HSD1. Furthermore, docking of itraconazole and posaconazole revealed steric clashes with Thr124, Thr222 and Ala226 of the 11ß-HSD1 substrate binding pocket, providing an explanation for their inactivity towards 11ß-HSD1. However, a major 
difference between $11 \beta$-HSD1 and $11 \beta$-HSD2 is the shape of the binding site entry. While Met233 flanks the binding site entry of $11 \beta$-HSD1, Arg212 replaces this amino acid at the analogous position in $11 \beta$-HSD2. The difference in size and electrostatic properties of these amino acids likely influences the inhibitory activity. Indeed, all $11 \beta$-HSD2 active compounds analyzed formed an interaction with Arg212. Furthermore, the extended azole scaffolds were found to form additional interactions in their docking poses with $11 \beta$-HSD2, pointing towards tighter binding to the protein. Interestingly, itraconazole and posaconazole did not fit entirely into the binding site of 11ß-HSD2 but rather lined the surface next to the binding site entry with their azole part (Fig. 5B). Moreover, the additional hydroxyl group of posaconazole was able to form several hydrogen bonds with the phosphate moiety of NADPH.

To rationalize the relative selectivity of the three azole compounds to inhibit human $11 \beta$-HSD2, they were also docked into the murine homology model [49]. The murine 11ß-HSD2 homology model revealed some crucial differences in the amino acid sequence compared to the human $11 \beta$ HSD2. Unlike the equivalent Arg212 on human 11ß-HSD2, Arg279 on mouse $11 \beta-H S D 2$ was not flanking the binding pocket entrance but oriented away (Fig. 5C). Furthermore, part of the binding cavity near the cofactor was occupied by Trp276, a residue located outside the binding pocket in human $11 \beta$-HSD2, and this residue caused itraconazole to adopt a different angle within the binding cavity in the docking simulation. Additionally, the docking poses for itraconazole predicted no hydrogen bonds with the protein (Fig. 5D). This missing structural anchoring provides an explanation for the weak activity of this fungicide towards murine $11 \beta$ HSD2. Interestingly, regarding murine $11 \beta$-HSD2, posaconazole and OHI showed greater inhibitory activity than itraconazole. Compared to itraconazole these two fungicides formed interactions with the cofactor via their hydroxyl groups (Figure 5E). 
One important aspect of in silico-driven screening studies is the analysis of the predictions and a possible refinement of the model that was used for screening. The screening model performance was very powerful, as all three azole fungicides identified by the model (tioconazole, sertaconazole and butoconazole) inhibited 11 -HSD1 enzyme activity at a concentration of 20 $\mu \mathrm{M}$ by at least $50 \%$. However, although itraconazole and posaconazole were represented in the DrugBank, they were not found by the model as virtual hits. A previous refinement study on this model [39], addressed the shape restriction as one major restrictivity aspect. Shape deletion and subsequent VS of all tested compounds, including OHI, with this model retrieved all compounds except for climbazole as hits. For more thorough VS for potential $11 \beta$-HSD inhibitors, the shapeless model version may therefore be more suitable.

\section{Discussion}

Molecular modeling-based in silico approaches are important in drug development for the identification of bioactive molecules. Pharmacophore-based VS is a powerful strategy to enrich potentially active compounds among a large number of test compounds, thereby facilitating the identification of drug lead structures [59]. Such in silico tools are also applied in anti-target screenings; however, in contrast to lead compound identification this is more challenging since this approach aims to identify all potentially harmful substances. The present study applied a pharmacophore model based on 11ß-HSD1 crystal structures for VS of the DrugBank database to find approved drugs that might inhibit 11 $\beta$-HSD2, an enzyme not included in current off-target screenings during drug development. The goal was to identify, as a first step, structural compound classes inhibiting 11ß-HSD2, followed by a more detailed analysis of a selected compound class including an in vitro validation of selected virtual hits. 
The pharmacophore model used in this study demonstrated already earlier high predictive power [60], and azole fungicides have been previously associated with $11 \beta$-HSDs: The azole fungicide triadimefon was reported to be a substrate of $11 \beta$-HSD1 $\left(\mathrm{K}_{\mathrm{m}} 3.5 \mu \mathrm{M}\right)$, thereby acting as a weak competitive inhibitor $\left(\mathrm{IC}_{50} 15 \mu \mathrm{M}\right)$ [51]. Ketoconazole was found to have weak inhibitory effects toward $11 \beta$-HSD1 and $11 \beta-H S D 2[39,61]$. Thus, this compound class was chosen for further

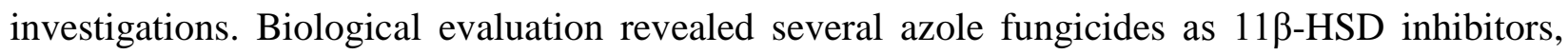
showing a significant structure-activity relationship between azole scaffold size and $11 \beta$-HSD enzyme selectivity and potency of inhibition. The large scaffolds of itraconazole and posaconazole, which were not initial VS hits, potently inhibited $11 \beta$-HSD2 enzyme activity. Compared to terconazole, which was considerably less active on $11 \beta-\mathrm{HSD} 2$, itraconazole and posaconazole contain an extended hydrophobic central region and an additional triazolone side chain, which may form additional stabilizing interactions with the binding pocket, including Arg212, thereby providing an explanation for the potent inhibition. Thus, the VS approach has proven useful to identify azole fungicides as 11ß-HSD2 inhibitors and to prioritize this compound class for further biological analyses, which were necessary to identify the most potent compounds itraconazole and posaconazole.

Itraconazole and posaconazole are clinically used for the prophylaxis and treatment of systemic mycotic infections and exert their mode of action by inhibiting the biosynthesis of ergosterol, an essential component of the fungal cell membrane $[62,63]$. They can be applied for a prolonged period of time, up to years when used as prophylactic treatment, especially in immunosuppressed patients [64]. After oral exposure, itraconazole is extensively metabolized in the liver by cytochrome P450 3A4 (CYP3A4) to its main metabolite OHI, which retains potent 11 $\beta$-HSD2 inhibitory activity. Thus, cortisol-dependent MR and GR activation due to prolonged 11 $\beta$-HSD2 inhibition may contribute to the observed adverse effects of these fungicides. In contrast to 

conjugation by UDP-glucuronyltransferase UGT1A4 [65]. Although posaconazole is not a substrate of CYP3A4, it acts like itraconazole and $\mathrm{OHI}$ as a potent CYP3A4 inhibitor and it is therefore prone to considerable pharmacokinetic interactions with CYP3A4 substrates, including glucocorticoids $[66,67]$. Inhibition of CYP3A4 by a single dose of itraconazole was shown to significantly decrease the formation clearance $\left(\mathrm{CL}_{\mathrm{f}}\right)$ of the metabolites $6 \beta$-hydroxycortisol and 6 $\beta$-hydroxycortisone [68]. Plasma cortisol and cortisone concentrations were not altered, indicating negative feedback regulation by the HPA axis and suggesting that cortisol levels are locally increased in CYP3A4 expressing tissues, particularly in the liver. Itraconazole, OHI and posaconazole might further promote local glucocorticoid effects by inhibiting P-glycoprotein (Pgp) mediated cortisol efflux $[69,70]$. Besides its important role in the liver, P-gp expression has been detected in the human placenta form the first trimester on towards full-term [71] and P-gp was shown in vitro to support the placental 11ß-HSD2 glucocorticoid barrier [72].

Inhibition of $11 \beta$-HSD2 by itraconazole and posaconazole might impair glucocorticoid inactivation in the kidney, colon, vasculature and placenta. Indeed, Denolle et al. reported a case study of a patient on long-term itraconazole treatment developing hypokalemia, edema, hypertension, low plasma renin and aldosterone concentrations and normal serum cortisol, typical symptoms of AME as a result of cortisol-dependent MR activation [73]. Similar side effects including hypokalemia, edema, hypertension and mildly reduced aldosterone serum levels were described by Sharkey et al. for several patients during long-term itraconazole use [74]. Importantly, the drug safety sheet of Sporanox ${ }^{\circledR}$ (itraconazole) reports hypokalemia and edema as occasionally $(\geq 1 / 1000,<1 / 100$ patients) occurring, whereas the safety sheet for the $i . v$. solution of Noxafil $^{\circledR}$ (posaconazole) notes hypokalemia as one of the most likely occurring adverse effect (22\% of the reports) and a rise in blood pressure as frequent $(1 / 100,<1 / 10)[75,76]$. 
Due to the high plasma protein binding capacity of itraconazole (99.8\%), OHI (99.6\%) and posaconazole ( $\geq 98 \%$ ), predominately to albumin, the circulating fraction of unbound drug is low $[75,76]$. However, in specific situations the plasma protein binding capacity can be reduced. Pregnancy leads to several metabolic and physiologic changes, including a decrease of serum albumin levels to about half of those in non-pregnant women. Considering this change, the unbound fraction of itraconazole/OHI and of posaconazole in plasma at steady state conditions during $200 \mathrm{mg}$ b.d.i. itraconazole or $400 \mathrm{mg}$ b.d.i posaconazole treatment $[75,77]$ can be roughly estimated to reach $\mathrm{IC}_{25}$ values of itraconazole $(78 \mathrm{nM})$ and posaconazole $(237 \mathrm{nM})$ for $11 \beta-\mathrm{HSD} 2$ as determined in HEK-293 cell lysates. Despite the high plasma protein binding ability, extensive extravascular distribution and accumulation in tissues are of considerable importance for these lipophilic compounds. Itraconazole was found to exceed plasma concentrations in fat tissue approximately 17 -fold and in lung, liver, muscle and kidney about 2-3 fold [64]. Less data are available for posaconazole, although it was shown that posaconazole concentrations are 31-42 fold higher in pulmonary alveolar cells compared with plasma [78]. Thus, the concentration of these triazole fungicides might also be elevated in placental tissue compared with plasma and therefore may reach relevant concentrations to inhibit 11ß-HSD2 enzyme activity.

Animal studies revealed embryotoxicity and teratogenicity with craniofacial and skeletal anomalies at concentrations exceeding the maximum recommended human dose by 5-20 fold during itraconazole treatment but at lower than therapeutic doses during posaconazole treatment $[75,76]$. Therefore, it is recommended to use these drugs in pregnancy only if the benefit outweighs the potential risk. Extrapolation of findings from animal studies to human is often difficult due to species-specific differences. The present study provides evidence for a considerably weaker inhibition of mouse and rat 11ß-HSD2 by itraconazole and $\mathrm{OHI}$, and lower activity of posaconazole towards the rodent enzymes. Thus, 11ß-HSD2-related effects on 
electrolyte balance, cardiovascular system and placental barrier function would be detected in rodent models only at much higher concentrations than in humans. Furthermore, regarding the latter, animal studies might be unreliable due to the highly variable 11ß-HSD2 expression levels during gestation between different species. Mouse placental 11 $\beta$-HSD2 mRNA drops towards late gestation, while rat placental $11 \beta-$ HSD2 reduction occurs later and less pronounced. In contrast, human placental 11 $\beta$-HSD2 levels are rising during gestation (reviewed by [13]).

In a prospective cohort study, de Santis et al. evaluated first trimester exposure to itraconazole in 206 pregnant women compared with 207 unexposed controls [79]. The mean duration of the therapy was $6.9 \pm 6.4$ days with a daily dose of $182 \pm 63 \mathrm{mg}$. No statistical difference between the exposed and the control group was found in terms of major congenital anomalies, premature birth or birth weight, but rates of live births and spontaneous abortion were higher in the exposed group. Bar-Oz et al. reported in a retrospective cohort study four times higher congenital malformation rates after first trimester exposure to itraconazole; however, strongly suggesting reporting bias due to retrospective data analysis [80]. The same authors found no difference in the rate of malformations compared to the control in a prospective cohort study with 229 women exposed to 50-800 $\mathrm{mg}$ itraconazole daily throughout $8.5 \pm 12.4$ days during the first trimester of pregnancy [81]. However, the rate live birth and the mean birth weight were lower in the exposed group compared to the control. No human data for prenatal posaconazole exposure have been published so far.

Developmental programming implies that an environmental factor affects fetal development during a sensitive time window to predispose the fetus towards diseases permanently throughout life [15]. A critical parameter includes the duration of the exposure to an environmental factor. The mean prenatal itraconazole exposure reported by de Santis et al. and Bar-Oz et al. was 6.98.5 days, thus shorter than the 15 days of treatment needed to reach plasma steady-state levels of 
itraconazole. This is important regarding $11 \beta-\mathrm{HSD} 2$ inhibition and thus prenatal programming through glucocorticoids. Several investigations found a reduction in birth weight in infants exposed to multiple courses of antenatal glucocorticoid therapy when adjusting for gestational age [82-84]. In addition, only first trimester itraconazole exposures were examined in the above described studies, but the effects of dexamethasone exposure on birth weight in rats was reported to be more pronounced when administered during later stages of pregnancy [85]. Chronic glucocorticoid treatment in mice was observed to impair the development of the cerebellum through inhibition of Sonic hedgehog (Shh) induced proliferation, a pathway important during embryonic growth and postembryonic tissue homeostasis. By upregulation of $11 \beta-\mathrm{HSD} 2$ expression Shh signaling partly antagonized the glucocorticoid-dependent effects, thus representing a feedback mechanism [86]. Interestingly, itraconazole, OHI and posaconazole were found to inhibit Shh signaling [87-89], which may result in downregulation of 11ß-HSD2 expression, thereby adding to the direct inhibitory effect of these azole fungicides.

Elevated glucocorticoid levels are known to inhibit angiogenesis, a crucial process during placental development that was shown to be inhibited by itraconazole $[88,90,91]$. Insufficient placental vascularization has been associated with intrauterine growth restriction, preeclampsia and fetal death, both in human and animal studies (reviewed by [92]).

In conclusion, itraconazole, $\mathrm{OHI}$ and posaconazole were identified as novel potent inhibitors of human $11 \beta-H S D 2$ by VS of the DrugBank database using an $11 \beta$-HSD pharmacophore model. Inhibition of placental $11 \beta-\mathrm{HSD} 2$ by these azole fungicides might contribute to an elevated local increase of cortisol levels, in addition to the known inhibition of cytochrome P450 enzymes and P-gp, thereby affecting fetal programming. Due to the observed species-specific differences, the consequences of placental 11ß-HSD2 inhibition may have been overlooked in preclinical studies 
using rodents, although similar biological responses might be detected in rodents, albeit at higher concentrations.

\section{Conflicts of Interest}

The authors declare no conflict of interest.

\section{Acknowledgements}

This work was supported by the Swiss National Science Foundation No 31003A-159454, the Austrian Science Fund (P26782), the Swiss Center for Applied Human Toxicology (SCAHT) and the Swiss Federal Office of Public Health (FOPH). A.O. was supported as Chair for Molecular and Systems Toxicology by the Novartis Research Foundation. D.S. is a Ingeborg Hochmair Professor at the University of Innsbruck. We thank Prof. Thierry Langer, University of Vienna, and Inte:Ligand $\mathrm{GmbH}$ for providing the LigandScout software.

\section{References}

[1] A. Odermatt, D.V. Kratschmar, Tissue-specific modulation of mineralocorticoid receptor function by 11ß-hydroxysteroid dehydrogenases: An overview, Mol Cell Endocrinol 350(2) (2012) 168-86.

[2] P. Ferrari, The role of $11 \beta$-hydroxysteroid dehydrogenase type 2 in human hypertension, Biochim Biophys Acta 1802 (2010) 1178-87.

[3] P.C. White, T. Mune, A.K. Agarwal, 11ß-Hydroxysteroid dehydrogenase and the syndrome of apparent mineralocorticoid excess, Endocr Rev 18(1) (1997) 135-56.

[4] M.I. New, L.S. Levine, E.G. Biglieri, J. Pareira, S. Ulick, Evidence for an unidentified steroid in a child with apparent mineralocorticoid hypertension, J Clin Endocrinol Metab 44(5) (1977) 924-33. 
[5] T. Mune, F.M. Rogerson, H. Nikkila, A.K. Agarwal, P.C. White, Human hypertension caused by mutations in the kidney isozyme of 11ß-hydroxysteroid dehydrogenase, Nat Genet 10(4) (1995) 394-9.

[6] S. Dave-Sharma, R.C. Wilson, M.D. Harbison, R. Newfield, M.R. Azar, Z.S. Krozowski, J.W. Funder, C.H. Shackleton, H.L. Bradlow, J.Q. Wei, J. Hertecant, A. Moran, R.E. Neiberger, J.W. Balfe, A. Fattah, D. Daneman, H.I. Akkurt, C. De Santis, M.I. New, Examination of genotype and phenotype relationships in 14 patients with apparent mineralocorticoid excess, $\mathrm{J}$ Clin Endocrinol Metab 83(7) (1998) 2244-54.

[7] E.P. Gomez-Sanchez, C.E. Gomez-Sanchez, Central hypertensinogenic effects of glycyrrhizic acid and carbenoxolone, Am J Physiol 263(6 Pt 1) (1992) E1125-30.

[8] I.Z. Beitins, F. Bayard, I.G. Ances, A. Kowarski, C.J. Migeon, The metabolic clearance rate, blood production, interconversion and transplacental passage of cortisol and cortisone in pregnancy near term, Pediatr Res 7(5) (1973) 509-19.

[9] R. Gitau, A. Cameron, N.M. Fisk, V. Glover, Fetal exposure to maternal cortisol, Lancet 352(9129) (1998) 707-8.

[10] R.W. Brown, K.E. Chapman, Y. Kotelevtsev, J.L. Yau, R.S. Lindsay, L. Brett, C. Leckie, P. Murad, V. Lyons, J.J. Mullins, C.R. Edwards, J.R. Seckl, Cloning and production of antisera to human placental 11ß-hydroxysteroid dehydrogenase type 2, Biochem J 313 ( Pt 3) (1996) 100717.

[11] R. Benediktsson, A.A. Calder, C.R. Edwards, J.R. Seckl, Placental 11 $\beta$-hydroxysteroid dehydrogenase: a key regulator of fetal glucocorticoid exposure, Clin Endocrinol (Oxf) 46(2) (1997) 161-6.

[12] C. Jung, J.T. Ho, D.J. Torpy, A. Rogers, M. Doogue, J.G. Lewis, R.J. Czajko, W.J. Inder, A longitudinal study of plasma and urinary cortisol in pregnancy and postpartum, J Clin Endocrinol Metab 96(5) (2011) 1533-40.

[13] A. Harris, J. Seckl, Glucocorticoids, prenatal stress and the programming of disease, Horm Behav 59(3) (2011) 279-89.

[14] E.C. Cottrell, J.R. Seckl, M.C. Holmes, C.S. Wyrwoll, Foetal and placental 11 $\beta$-HSD2: a hub for developmental programming, Acta Physiol (Oxf) 210(2) (2014) 288-95. [15] D.J. Barker, The developmental origins of adult disease, J Am Coll Nutr 23(6 Suppl) (2004) 588S-595S. 

Elevated plasma cortisol concentrations: a link between low birth weight and the insulin resistance syndrome?, J Clin Endocrinol Metab 83(3) (1998) 757-60.

[17] N.P. French, R. Hagan, S.F. Evans, M. Godfrey, J.P. Newnham, Repeated antenatal corticosteroids: size at birth and subsequent development, Am J Obstet Gynecol 180(1 Pt 1) (1999) 114-21.

[18] J.R. Seckl, Prenatal glucocorticoids and long-term programming, Eur J Endocrinol 151 Suppl 3 (2004) U49-62.

[19] M. Shams, M.D. Kilby, D.A. Somerset, A.J. Howie, A. Gupta, P.J. Wood, M. Afnan, P.M. Stewart, 11 $\beta$-hydroxysteroid dehydrogenase type 2 in human pregnancy and reduced expression in intrauterine growth restriction, Hum Reprod 13(4) (1998) 799-804.

[20] R. Benediktsson, R.S. Lindsay, J. Noble, J.R. Seckl, C.R. Edwards, Glucocorticoid exposure in utero: new model for adult hypertension, Lancet 341(8841) (1993) 339-41.

[21] J. Dy, H. Guan, R. Sampath-Kumar, B.S. Richardson, K. Yang, Placental 11ßhydroxysteroid dehydrogenase type 2 is reduced in pregnancies complicated with idiopathic intrauterine growth Restriction: evidence that this is associated with an attenuated ratio of cortisone to cortisol in the umbilical artery, Placenta 29(2) (2008) 193-200.

[22] C.L. McTernan, N. Draper, H. Nicholson, S.M. Chalder, P. Driver, M. Hewison, M.D. Kilby, P.M. Stewart, Reduced placental 11 $\beta$-hydroxysteroid dehydrogenase type 2 mRNA levels in human pregnancies complicated by intrauterine growth restriction: an analysis of possible mechanisms, J Clin Endocrinol Metab 86(10) (2001) 4979-83.

[23] R. Benediktsson, J. Brennand, L. Tibi, A.A. Calder, J.R. Seckl, C.R. Edwards, Fetal osteocalcin levels are related to placental $11 \beta$-hydroxysteroid dehydrogenase activity in humans, Clin Endocrinol (Oxf) 42(5) (1995) 551-5.

[24] A.G. Rebuffat, S. Tam, A.R. Nawrocki, M.E. Baker, B.M. Frey, F.J. Frey, A. Odermatt, The 11-ketosteroid 11-ketodexamethasone is a glucocorticoid receptor agonist, Mol Cell Endocrinol 214(1-2) (2004) 27-37.

[25] L.A. Welberg, J.R. Seckl, M.C. Holmes, Prenatal glucocorticoid programming of brain corticosteroid receptors and corticotrophin-releasing hormone: possible implications for behaviour, Neuroscience 104(1) (2001) 71-9.

[26] L.A. Welberg, J.R. Seckl, M.C. Holmes, Inhibition of 11 $\beta$-hydroxysteroid dehydrogenase, the foeto-placental barrier to maternal glucocorticoids, permanently programs amygdala GR 

54.

[27] R.S. Lindsay, R.M. Lindsay, C.R. Edwards, J.R. Seckl, Inhibition of 11 $\beta$-hydroxysteroid dehydrogenase in pregnant rats and the programming of blood pressure in the offspring, Hypertension 27(6) (1996) 1200-4.

[28] C.S. Wyrwoll, J.R. Seckl, M.C. Holmes, Altered placental function of 11ß-hydroxysteroid dehydrogenase 2 knockout mice, Endocrinology 150(3) (2009) 1287-93.

[29] J. Mairesse, J. Lesage, C. Breton, B. Breant, T. Hahn, M. Darnaudery, S.L. Dickson, J. Seckl, B. Blondeau, D. Vieau, S. Maccari, O. Viltart, Maternal stress alters endocrine function of the feto-placental unit in rats, Am J Physiol Endocrinol Metab 292(6) (2007) E1526-33.

[30] S.C. Langley-Evans, G.J. Phillips, R. Benediktsson, D.S. Gardner, C.R. Edwards, A.A. Jackson, J.R. Seckl, Protein intake in pregnancy, placental glucocorticoid metabolism and the programming of hypertension in the rat, Placenta 17(2-3) (1996) 169-72.

[31] D. Vieau, N. Sebaai, M. Leonhardt, I. Dutriez-Casteloot, O. Molendi-Coste, C. Laborie, C. Breton, S. Deloof, J. Lesage, HPA axis programming by maternal undernutrition in the male rat offspring, Psychoneuroendocrinology 32 Suppl 1 (2007) S16-20.

[32] J.R. Seckl, M.C. Holmes, Mechanisms of disease: glucocorticoids, their placental metabolism and fetal 'programming' of adult pathophysiology, Nat Clin Pract Endocrinol Metab 3(6) (2007) 479-88.

[33] A. Odermatt, C. Gumy, Glucocorticoid and mineralocorticoid action: why should we consider influences by environmental chemicals?, Biochem Pharmacol 76(10) (2008) 1184-93.

[34] T.E. Strandberg, S. Andersson, A.L. Jarvenpaa, P.M. McKeigue, Preterm birth and licorice consumption during pregnancy, Am J Epidemiol 156(9) (2002) 803-5.

[35] K. Raikkonen, J.R. Seckl, K. Heinonen, R. Pyhala, K. Feldt, A. Jones, A.K. Pesonen, D.I. Phillips, J. Lahti, A.L. Jarvenpaa, J.G. Eriksson, K.A. Matthews, T.E. Strandberg, E. Kajantie, Maternal prenatal licorice consumption alters hypothalamic-pituitary-adrenocortical axis function in children, Psychoneuroendocrinology 35(10) (2010) 1587-93.

[36] K. Raikkonen, A.K. Pesonen, K. Heinonen, J. Lahti, N. Komsi, J.G. Eriksson, J.R. Seckl, A.L. Jarvenpaa, T.E. Strandberg, Maternal licorice consumption and detrimental cognitive and psychiatric outcomes in children, Am J Epidemiol 170(9) (2009) 1137-46.

[37] E. Schoof, M. Girstl, W. Frobenius, M. Kirschbaum, H.G. Dorr, W. Rascher, J. Dotsch, Decreased gene expression of 11ß-hydroxysteroid dehydrogenase type 2 and 15- 
hydroxyprostaglandin dehydrogenase in human placenta of patients with preeclampsia, J Clin Endocrinol Metab 86(3) (2001) 1313-7.

[38] M. Aufdenblatten, M. Baumann, L. Raio, B. Dick, B.M. Frey, H. Schneider, D. Surbek, B. Hocher, M.G. Mohaupt, Prematurity is related to high placental cortisol in preeclampsia, Pediatr Res 65(2) (2009) 198-202.

[39] A. Vuorinen, L.G. Nashev, A. Odermatt, J.M. Rollinger, D. Schuster, Pharmacophore Model Refinement for 11ß-Hydroxysteroid Dehydrogenase Inhibitors: Search for Modulators of Intracellular Glucocorticoid Concentrations, Mol Inform 33(1) (2014) 15-25.

[40] D. Schuster, E.M. Maurer, C. Laggner, L.G. Nashev, T. Wilckens, T. Langer, A. Odermatt, The discovery of new 11 -hydroxysteroid dehydrogenase type 1 inhibitors by common feature pharmacophore modeling and virtual screening, J Med Chem 49(12) (2006) 3454-66.

[41] D.V. Kratschmar, A. Vuorinen, T. Da Cunha, G. Wolber, D. Classen-Houben, O. Doblhoff, D. Schuster, A. Odermatt, Characterization of activity and binding mode of glycyrrhetinic acid derivatives inhibiting 11 $\beta$-hydroxysteroid dehydrogenase type 2, J Steroid Biochem Mol Biol 125(1-2) (2011) 129-42.

[42] A.G. Atanasov, S. Tam, J.M. Rocken, M.E. Baker, A. Odermatt, Inhibition of $11 \beta$ hydroxysteroid dehydrogenase type 2 by dithiocarbamates, Biochem Biophys Res Commun 308(2) (2003) 257-62.

[43] C. Furstenberger, A. Vuorinen, T. Da Cunha, D.V. Kratschmar, M. Saugy, D. Schuster, A. Odermatt, The anabolic androgenic steroid fluoxymesterone inhibits $11 \beta$-hydroxysteroid dehydrogenase 2-dependent glucocorticoid inactivation, Toxicol Sci 126(2) (2012) 353-61.

[44] A. Vuorinen, R. Engeli, A. Meyer, F. Bachmann, U.J. Griesser, D. Schuster, A. Odermatt, Ligand-based pharmacophore modeling and virtual screening for the discovery of novel $17 \beta$ hydroxysteroid dehydrogenase 2 inhibitors, J Med Chem 57(14) (2014) 5995-6007.

[45] P.K. Smith, R.I. Krohn, G.T. Hermanson, A.K. Mallia, F.H. Gartner, M.D. Provenzano, E.K. Fujimoto, N.M. Goeke, B.J. Olson, D.C. Klenk, Measurement of protein using bicinchoninic acid, Anal Biochem 150(1) (1985) 76-85.

[46] G. Jones, P. Willett, R.C. Glen, A.R. Leach, R. Taylor, Development and validation of a genetic algorithm for flexible docking, J Mol Biol 267(3) (1997) 727-48.

[47] Z.K. Wan, E. Chenail, J. Xiang, H.Q. Li, M. Ipek, J. Bard, K. Svenson, T.S. Mansour, X. Xu, X. Tian, V. Suri, S. Hahm, Y. Xing, C.E. Johnson, X. Li, A. Qadri, D. Panza, M. Perreault, 

induced obesity mouse model, J Med Chem 52(17) (2009) 5449-61.

[48] H. Yamaguchi, T. Akitaya, T. Yu, Y. Kidachi, K. Kamiie, T. Noshita, H. Umetsu, K. Ryoyama, Homology modeling and structural analysis of $11 \beta$-hydroxysteroid dehydrogenase type 2, Eur J Med Chem 46(4) (2011) 1325-30.

[49] H. Yamaguchi, T. Akitaya, Y. Kidachi, K. Kamiie, T. Noshita, H. Umetsu, K. Ryoyama, Mouse 11ß-hydroxysteroid dehydrogenase type 2 for human application: homology modeling, structural analysis and ligand-receptor interaction, Cancer Inform 10 (2011) 287-95.

[50] G. Wolber, T. Langer, LigandScout: 3-D pharmacophores derived from protein-bound ligands and their use as virtual screening filters, J Chem Inf Model 45(1) (2005) 160-9.

[51] A. Meyer, A. Vuorinen, A.E. Zielinska, T. Da Cunha, P. Strajhar, G.G. Lavery, D. Schuster, A. Odermatt, Carbonyl reduction of triadimefon by human and rodent $11 \beta$-hydroxysteroid dehydrogenase 1, Biochem Pharmacol 85(9) (2013) 1370-8.

[52] T. Kaserer, K.R. Beck, M. Akram, A. Odermatt, D. Schuster, Pharmacophore Models and Pharmacophore-Based Virtual Screening: Concepts and Applications Exemplified on Hydroxysteroid Dehydrogenases, Molecules 20(12) (2015) 22799-832.

[53] A.G. Atanasov, L.G. Nashev, S. Tam, M.E. Baker, A. Odermatt, Organotins disrupt the 11 $\beta$ hydroxysteroid dehydrogenase type 2-dependent local inactivation of glucocorticoids, Environ Health Perspect 113(11) (2005) 1600-6.

[54] M.V. Mustonen, V.V. Isomaa, T. Vaskivuo, J. Tapanainen, M.H. Poutanen, F. Stenback, R.K. Vihko, P.T. Vihko, Human 17ß-hydroxysteroid dehydrogenase type 2 messenger ribonucleic acid expression and localization in term placenta and in endometrium during the menstrual cycle, J Clin Endocrinol Metab 83(4) (1998) 1319-24.

[55] J. Takeyama, H. Sasano, T. Suzuki, K. Iinuma, H. Nagura, S. Andersson, 17 $\beta$ hydroxysteroid dehydrogenase types 1 and 2 in human placenta: an immunohistochemical study with correlation to placental development, J Clin Endocrinol Metab 83(10) (1998) 3710-5.

[56] S. Arampatzis, B. Kadereit, D. Schuster, Z. Balazs, R.A. Schweizer, F.J. Frey, T. Langer, A. Odermatt, Comparative enzymology of $11 \beta$-hydroxysteroid dehydrogenase type 1 from six species, J Mol Endocrinol 35(1) (2005) 89-101.

[57] A.G. Atanasov, I.D. Ignatova, L.G. Nashev, B. Dick, P. Ferrari, F.J. Frey, A. Odermatt, Impaired protein stability of $11 \beta$-hydroxysteroid dehydrogenase type 2 : a novel mechanism of apparent mineralocorticoid excess, J Am Soc Nephrol 18(4) (2007) 1262-70. 
[58] P. Ferrari, R.E. Smith, J.W. Funder, Z.S. Krozowski, Substrate and inhibitor specificity of the cloned human 11ß-hydroxysteroid dehydrogenase type 2 isoform, Am J Physiol 270(5 Pt 1) (1996) E900-4.

[59] D. Schuster, 3D pharmacophores as tools for activity profiling, Drug Discov Today Technol 7(4) (2010) 205-211.

[60] L.G. Nashev, A. Vuorinen, L. Praxmarer, B. Chantong, D. Cereghetti, R. Winiger, D. Schuster, A. Odermatt, Virtual screening as a strategy for the identification of xenobiotics disrupting corticosteroid action, PLoS One 7(10) (2012) e46958.

[61] S. Diederich, C. Grossmann, B. Hanke, M. Quinkler, M. Herrmann, V. Bahr, W. Oelkers, In

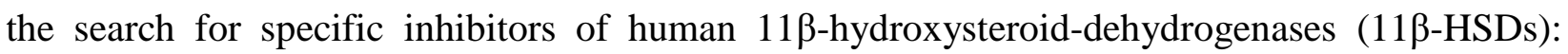
chenodeoxycholic acid selectively inhibits 11ß-HSD-I, Eur J Endocrinol 142(2) (2000) 200-7.

[62] M.I. Morris, Posaconazole: a new oral antifungal agent with an expanded spectrum of activity, Am J Health Syst Pharm 66(3) (2009) 225-36.

[63] N.H. Georgopapadakou, T.J. Walsh, Antifungal agents: chemotherapeutic targets and immunologic strategies, Antimicrob Agents Chemother 40(2) (1996) 279-91.

[64] L. Willems, R. van der Geest, K. de Beule, Itraconazole oral solution and intravenous formulations: a review of pharmacokinetics and pharmacodynamics, J Clin Pharm Ther 26(3) (2001) 159-69.

[65] A. Ghosal, N. Hapangama, Y. Yuan, J. Achanfuo-Yeboah, R. Iannucci, S. Chowdhury, K. Alton, J.E. Patrick, S. Zbaida, Identification of human UDP-glucuronosyltransferase enzyme(s) responsible for the glucuronidation of posaconazole (Noxafil), Drug Metab Dispos 32(2) (2004) 267-71.

[66] N. Isoherranen, K.L. Kunze, K.E. Allen, W.L. Nelson, K.E. Thummel, Role of itraconazole metabolites in CYP3A4 inhibition, Drug Metab Dispos 32(10) (2004) 1121-31.

[67] D. Wexler, R. Courtney, W. Richards, C. Banfield, J. Lim, M. Laughlin, Effect of posaconazole on cytochrome P450 enzymes: a randomized, open-label, two-way crossover study, Eur J Pharm Sci 21(5) (2004) 645-53.

[68] C.C. Peng, I. Templeton, K.E. Thummel, C. Davis, K.L. Kunze, N. Isoherranen, Evaluation of $6 \beta$-hydroxycortisol, $6 \beta$-hydroxycortisone, and a combination of the two as endogenous probes for inhibition of CYP3A4 in vivo, Clin Pharmacol Ther 89(6) (2011) 888-95.

[69] L.M. Vermeer, C.D. Isringhausen, B.W. Ogilvie, D.B. Buckley, Evaluation of Ketoconazole and Its Alternative Clinical CYP3A4/5 Inhibitors as Inhibitors of Drug Transporters: The In Vitro 
Effects of Ketoconazole, Ritonavir, Clarithromycin, and Itraconazole on 13 Clinically-Relevant Drug Transporters, Drug Metab Dispos 44(3) (2016) 453-9.

[70] A.H. Saad, D.D. DePestel, P.L. Carver, Factors influencing the magnitude and clinical significance of drug interactions between azole antifungals and select immunosuppressants, Pharmacotherapy 26(12) (2006) 1730-44.

[71] M. Ceckova-Novotna, P. Pavek, F. Staud, P-glycoprotein in the placenta: expression, localization, regulation and function, Reprod Toxicol 22(3) (2006) 400-10.

[72] P.J. Mark, B.J. Waddell, P-glycoprotein restricts access of cortisol and dexamethasone to the glucocorticoid receptor in placental BeWo cells, Endocrinology 147(11) (2006) 5147-52.

[73] T. Denolle, M. Azizi, C. Massart, M.C. Zennaro, Itraconazole: a new drug-related cause of hypertension, Ann Cardiol Angeiol (Paris) 63(3) (2014) 213-5.

[74] P.K. Sharkey, M.G. Rinaldi, J.F. Dunn, T.C. Hardin, R.J. Fetchick, J.R. Graybill, High-dose itraconazole in the treatment of severe mycoses, Antimicrob Agents Chemother 35(4) (1991) 707-13.

[75] Janssen-Cilag-AG, Sporanox drug safety sheet, (2015).

[76] MSD-MERCK-SHARP\&DOHME-AG, NOXAFIL Inf Konz $18 \mathrm{mg} / \mathrm{ml}$ drug safety sheet, (2014).

[77] R. Courtney, S. Pai, M. Laughlin, J. Lim, V. Batra, Pharmacokinetics, safety, and tolerability of oral posaconazole administered in single and multiple doses in healthy adults, Antimicrob Agents Chemother 47(9) (2003) 2788-95.

[78] J.E. Conte, Jr., J.A. Golden, G. Krishna, M. McIver, E. Little, E. Zurlinden, Intrapulmonary pharmacokinetics and pharmacodynamics of posaconazole at steady state in healthy subjects, Antimicrob Agents Chemother 53(2) (2009) 703-7.

[79] M. De Santis, E. Di Gianantonio, E. Cesari, G. Ambrosini, G. Straface, M. Clementi, Firsttrimester itraconazole exposure and pregnancy outcome: a prospective cohort study of women contacting teratology information services in Italy, Drug Saf 32(3) (2009) 239-44.

[80] B. Bar-Oz, M.E. Moretti, G. Mareels, T. Van Tittelboom, G. Koren, Reporting bias in retrospective ascertainment of drug-induced embryopathy, Lancet 354(9191) (1999) 1700-1.

[81] B. Bar-Oz, M.E. Moretti, R. Bishai, G. Mareels, T. Van Tittelboom, J. Verspeelt, G. Koren, Pregnancy outcome after in utero exposure to itraconazole: a prospective cohort study, Am J Obstet Gynecol 183(3) (2000) 617-20. 
[82] K.E. Murphy, M.E. Hannah, A.R. Willan, S.A. Hewson, A. Ohlsson, E.N. Kelly, S.G. Matthews, S. Saigal, E. Asztalos, S. Ross, M.F. Delisle, K. Amankwah, P. Guselle, A. Gafni, S.K. Lee, B.A. Armson, Multiple courses of antenatal corticosteroids for preterm birth (MACS): a randomised controlled trial, Lancet 372(9656) (2008) 2143-51.

[83] R.J. Wapner, Y. Sorokin, E.A. Thom, F. Johnson, D.J. Dudley, C.Y. Spong, A.M. Peaceman, K.J. Leveno, M. Harper, S.N. Caritis, M. Miodovnik, B. Mercer, J.M. Thorp, A. Moawad, M.J. O'Sullivan, S. Ramin, M.W. Carpenter, D.J. Rouse, B. Sibai, S.G. Gabbe, Single versus weekly courses of antenatal corticosteroids: evaluation of safety and efficacy, Am J Obstet Gynecol 195(3) (2006) 633-42.

[84] E. Bevilacqua, R. Brunelli, M.M. Anceschi, Review and meta-analysis: Benefits and risks of multiple courses of antenatal corticosteroids, J Matern Fetal Neona 23(4) (2010) 244-60.

[85] M.J. Nyirenda, R.S. Lindsay, C.J. Kenyon, A. Burchell, J.R. Seckl, Glucocorticoid exposure in late gestation permanently programs rat hepatic phosphoenolpyruvate carboxykinase and glucocorticoid receptor expression and causes glucose intolerance in adult offspring, J Clin Invest 101(10) (1998) 2174-81.

[86] V.M. Heine, D.H. Rowitch, Hedgehog signaling has a protective effect in glucocorticoidinduced mouse neonatal brain injury through an 11ß-HSD2-dependent mechanism, J Clin Invest 119(2) (2009) 267-77.

[87] J. Kim, J.Y. Tang, R. Gong, J.J. Lee, K.V. Clemons, C.R. Chong, K.S. Chang, M. Fereshteh, D. Gardner, T. Reya, J.O. Liu, E.H. Epstein, D.A. Stevens, P.A. Beachy, Itraconazole, a commonly used antifungal that inhibits Hedgehog pathway activity and cancer growth, Cancer Cell 17(4) (2010) 388-99.

[88] J.R. Pace, A.M. DeBerardinis, V. Sail, S.K. Tacheva-Grigorova, K.A. Chan, R. Tran, D.S. Raccuia, R.J. Wechsler-Reya, M.K. Hadden, Repurposing the Clinically Efficacious Antifungal Agent Itraconazole as an Anticancer Chemotherapeutic, J Med Chem 59(8) (2016) 3635-49.

[89] B. Chen, V. Trang, A. Lee, N.S. Williams, A.N. Wilson, E.H. Epstein, Jr., J.Y. Tang, J. Kim, Posaconazole, a Second-Generation Triazole Antifungal Drug, Inhibits the Hedgehog Signaling Pathway and Progression of Basal Cell Carcinoma, Mol Cancer Ther 15(5) (2016) 86676.

[90] C.R. Chong, J. Xu, J. Lu, S. Bhat, D.J. Sullivan, Jr., J.O. Liu, Inhibition of angiogenesis by the antifungal drug itraconazole, ACS Chem Biol 2(4) (2007) 263-70. 
[91] R. Del Carratore, A. Carpi, P. Beffy, V. Lubrano, L. Giorgetti, B.E. Maserti, M.A. Carluccio, M. Simili, G. Iervasi, S. Balzan, Itraconazole inhibits HMEC-1 angiogenesis, Biomed Pharmacother 66(4) (2012) 312-7.

[92] E.V. Khankin, C. Royle, S.A. Karumanchi, Placental vasculature in health and disease, Semin Thromb Hemost 36(3) (2010) 309-20. 


\section{Figure Legends}

Fig. 1. Pharmacophore model used for virtual screening of the DrugBank database. (A) The model consists of four hydrophobic $(\mathrm{H})$ features (cyan), two hydrogen bond acceptors (HBA, green) and a sterical shape restriction (grey) [39]. (B) Virtual hits from the DrugBank screening fitted into the model. Compounds are color-coded: red - tioconazole; green - butoconazole; violet - sertaconazole.

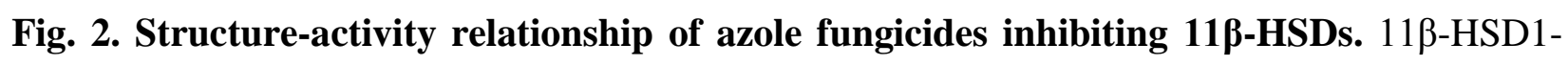
dependent reduction of cortisone $(200 \mathrm{nM})$ to cortisol and 11 $\beta$-HSD2-dependent oxidation of cortisol $(200 \mathrm{nM})$ to cortisone were measured using HEK-293 cell lysates in the presence of 500 $\mu \mathrm{M}$ NADPH or $\mathrm{NAD}^{+}$, respectively. Residual enzyme activity upon exposure to $20 \mu \mathrm{M}$ test substance (mean $\pm \mathrm{SD}$ ) and $\mathrm{IC}_{50}$ values (mean $\pm \mathrm{SD}$ ) were obtained from three independent experiments. For compounds with residual enzyme activities ( $\%$ of control) $>40 \%$, at a compound concentration of $20 \mu \mathrm{M}, \mathrm{IC}_{50}$ values were not determined (n.d.). a, values reported earlier by Vuorinen et al. [39].

Fig. 3. Inhibition of 11ß-HSD2 enzyme activity determined in HEK-293 cell lysates. Lysates

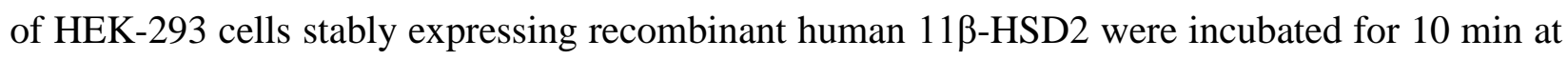
$37^{\circ} \mathrm{C}$ with $200 \mathrm{nM}$ radiolabeled cortisol, $500 \mu \mathrm{M} \mathrm{NAD}{ }^{+}$and increasing concentrations of itraconazole $(\mathrm{A})$, hydroxyitraconazole $(\mathrm{OHI})(\mathrm{B})$ and posaconazole $(\mathrm{C})$. The substrate conversion was determined and compared to the enzyme activity in the control samples (0.1\% DMSO). Data represent mean \pm SD from three independent experiments. 


\begin{abstract}
Fig. 4. Inhibition of rat and mouse 11ß-HSD2 activity measured in kidney homogenates, compared to human 11ß-HSD2 in HEK-293 cell lysates. Rat and mouse kidney homogenates were incubated for $20 \mathrm{~min}$ at $37^{\circ} \mathrm{C}$ with $50 \mathrm{nM}$ radiolabeled corticosterone in the absence or presence of $10 \mu \mathrm{M}$ itraconazole (A), $10 \mu \mathrm{M}$ hydroxyitraconazole (OHI) (B) or $10 \mu \mathrm{M}$ posaconazole (C). Human 11 $\beta$-HSD2 activity was measured in HEK-293 cells stably expressing recombinant human $11 \beta-\mathrm{HSD} 2$ upon incubation for $10 \mathrm{~min}$ at $37^{\circ} \mathrm{C}$ with $200 \mathrm{nM}$ radiolabeled cortisol, $500 \mu \mathrm{M} \mathrm{NAD}{ }^{+}$and the corresponding concentration of azole fungicide $(10 \mu \mathrm{M}$ itraconazole, $10 \mu \mathrm{M}$ posaconazole or $5 \mu \mathrm{M}$ OHI). The substrate conversion was calculated (in nmoles/min) and normalized to the enzyme activity in the control sample (0.1\% DMSO). Data represent mean $\pm \mathrm{SD}$ from at least three independent experiments. a, $5 \mu \mathrm{M}$ was used (due to complete inhibition higher concentrations were not analyzed).
\end{abstract}

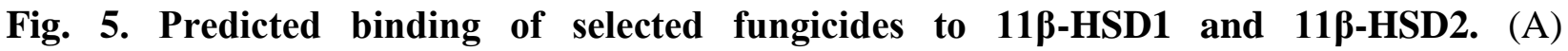

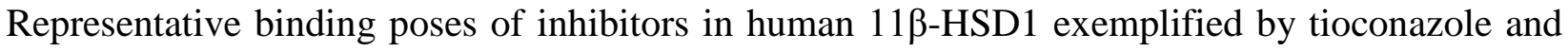
sertaconazole. Important interactions for protein-ligand binding and the cofactor are shown in ball-and-stick style. Hydrophobic contacts between the ligand and the binding site are represented as yellow spheres, the HBA to Ala172 as red arrow and the aromatic stacking with Tyr183 as blue circle. (B) Binding mode of itraconazole docked into the homology model of human $11 \beta$ HSD2. (C) Itraconazole docked into the homology model of murine 11ß-HSD2. Arg279 (equivalent to Arg212 in human 11ß-HSD2) is pointing away from the binding pocket, while Trp276 blocks the binding pocket next to the cofactor NADPH. (D) Itraconazole docked into the homology model of murine $11 \beta-H S D 2$. The ligand is not anchored via hydrogen bonds or charged interactions, only hydrophobic contacts (yellow spheres) are formed. (E) Posaconazole (grey) and OHI (green) docked into murine 11ß-HSD2. Their hydroxyl groups form hydrogen 
bonds (green arrow) with the cofactor, which provides an explanation for their higher activity compared to itraconazole. 

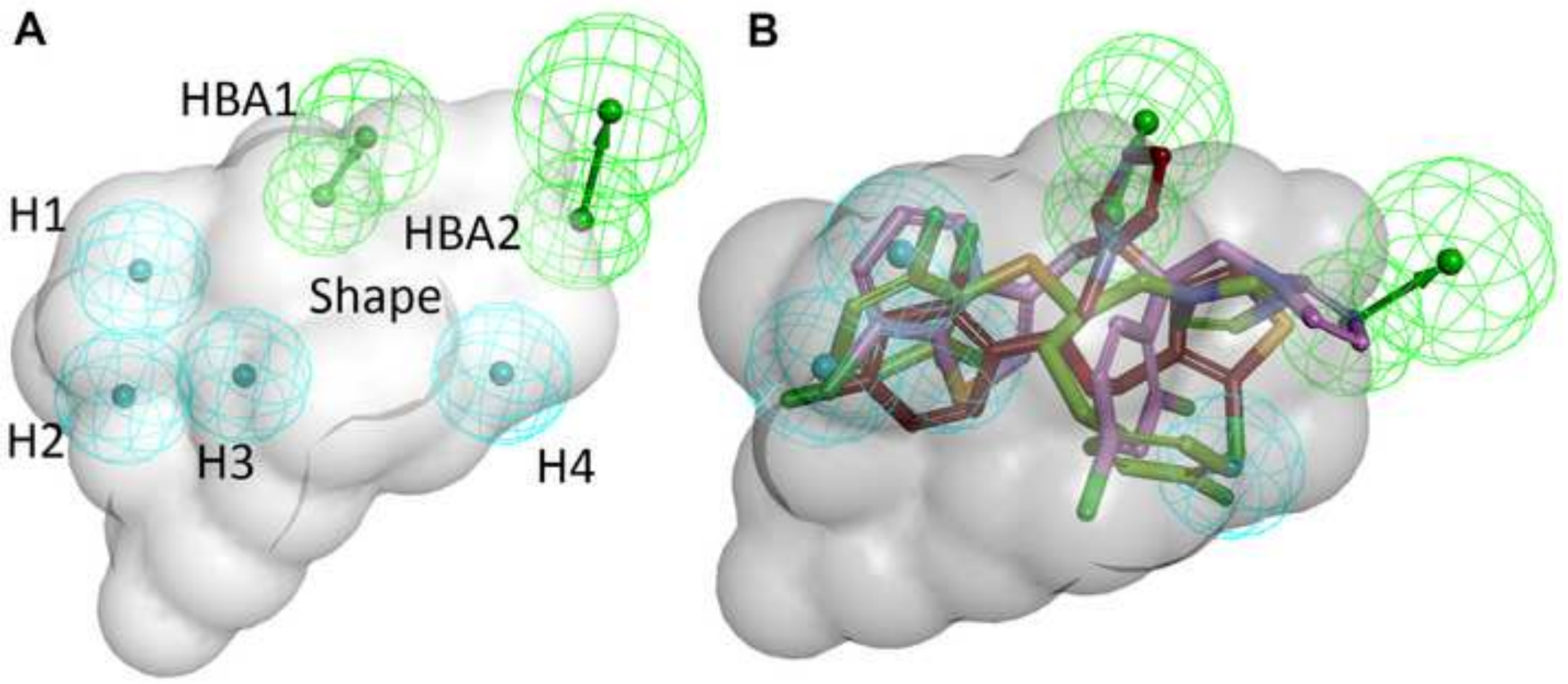
Click here to download high resolution image

\begin{tabular}{|c|c|c|c|c|c|}
\hline \multirow{2}{*}{ compound } & \multirow{2}{*}{ structure } & \multicolumn{2}{|c|}{$\begin{array}{l}\text { residual enzyme activity } \\
{[\% \text { of control] }(20 \mu \mathrm{M})}\end{array}$} & \multicolumn{2}{|c|}{$I_{50}$ values $[\mu \mathrm{M}]$} \\
\hline & & $11 \beta$-HSD1 & $11 \beta$-HSD2 & $11 \beta$-HSD1 & $11 \beta$-HSD 2 \\
\hline Albendazole & & $105 \pm 5$ & $100 \pm 15$ & n.d. & n.d. \\
\hline Climbazole & & $57 \pm 10$ & $86 \pm 12$ & n.d. & n.d. \\
\hline Tioconazole & & $18 \pm 3$ & $44 \pm 5$ & $4.97 \pm 0.64$ & n.d. \\
\hline Sertaconazole & & $35 \pm 3$ & $61 \pm 5$ & $12.73 \pm 1.69$ & n.d. \\
\hline Butoconazole & & $48 \pm 6$ & $50 \pm 6$ & n.d. & n.d. \\
\hline Ketoconazole & & $67 \pm 4^{a}$ & $26 \pm 2^{a}$ & n.d. & n.d. \\
\hline Terconazole & & $97 \pm 6$ & $62 \pm 5$ & n.d. & n.d. \\
\hline Posaconazole & & $88 \pm 11$ & $8 \pm 5$ & n.d. & $0.460 \pm 0.098$ \\
\hline Itraconazole & & $89 \pm 6$ & $4 \pm 3$ & n.d. & $0.139 \pm 0.014$ \\
\hline
\end{tabular}

residual enzyme activity

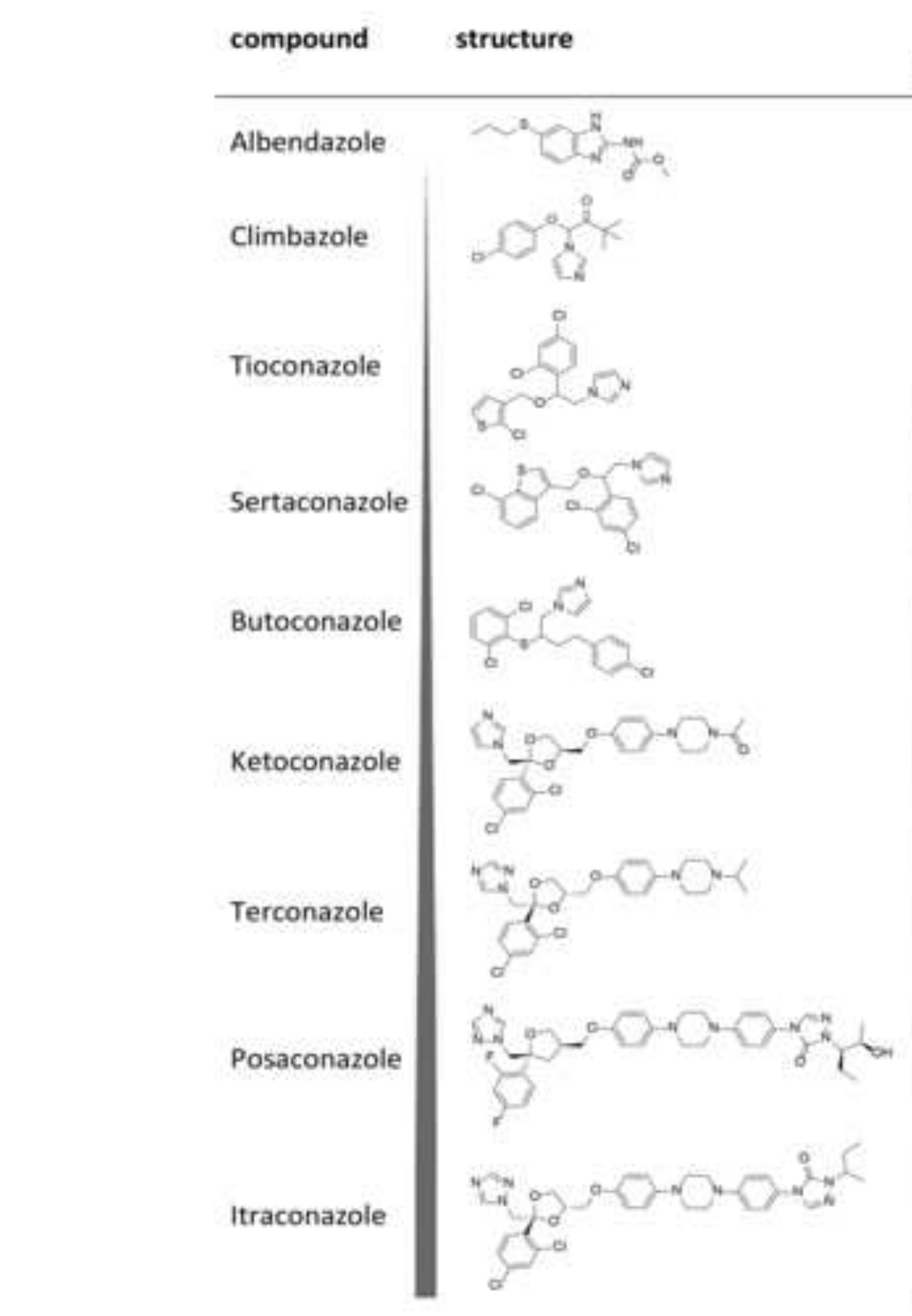

\section{[\% of control] $(20 \mu \mathrm{M})$}

$105 \pm$

\begin{tabular}{|c|c|c|c|c|c|}
\hline \multirow{2}{*}{ compound } & \multirow{2}{*}{ structure } & \multicolumn{2}{|c|}{$\begin{array}{c}\text { residual enzyme activity } \\
\text { [\% of control] }(20 \mu \mathrm{M})\end{array}$} & \multicolumn{2}{|c|}{$\mathrm{IC}_{50}$ values $[\mu \mathrm{M}]$} \\
\hline & & $11 \beta$-HSD1 & $11 \beta$-HSD2 & $11 \beta$-HSD 1 & $11 \beta-H S D 2$ \\
\hline Albendazole & & $105 \pm 5$ & $100 \pm 15$ & n.d. & n.d. \\
\hline Climbazole & & $57 \pm 10$ & $86 \pm 12$ & n.d. & n.d. \\
\hline Tioconazole & & $18 \pm 3$ & $44 \pm 5$ & $4.97 \pm 0.64$ & n.d. \\
\hline Sertaconazole & & $35 \pm 3$ & $61 \pm 5$ & $12.73 \pm 1.69$ & n.d. \\
\hline Butoconazole & & $48 \pm 6$ & $50 \pm 6$ & n.d. & n.d. \\
\hline Ketoconazole & & $67 \pm 4^{a}$ & $26 \pm 2^{a}$ & n.d. & n.d. \\
\hline Terconazole & & $97 \pm 6$ & $62 \pm 5$ & n.d. & n.d. \\
\hline Posaconazole & & $88 \pm 11$ & $8 \pm 5$ & n.d. & $0.460 \pm 0.098$ \\
\hline Itraconazole & & $89 \pm 6$ & $4 \pm 3$ & n.d. & $0.139 \pm 0.014$ \\
\hline
\end{tabular}




\section{Figure3}

Click here to download high resolution image
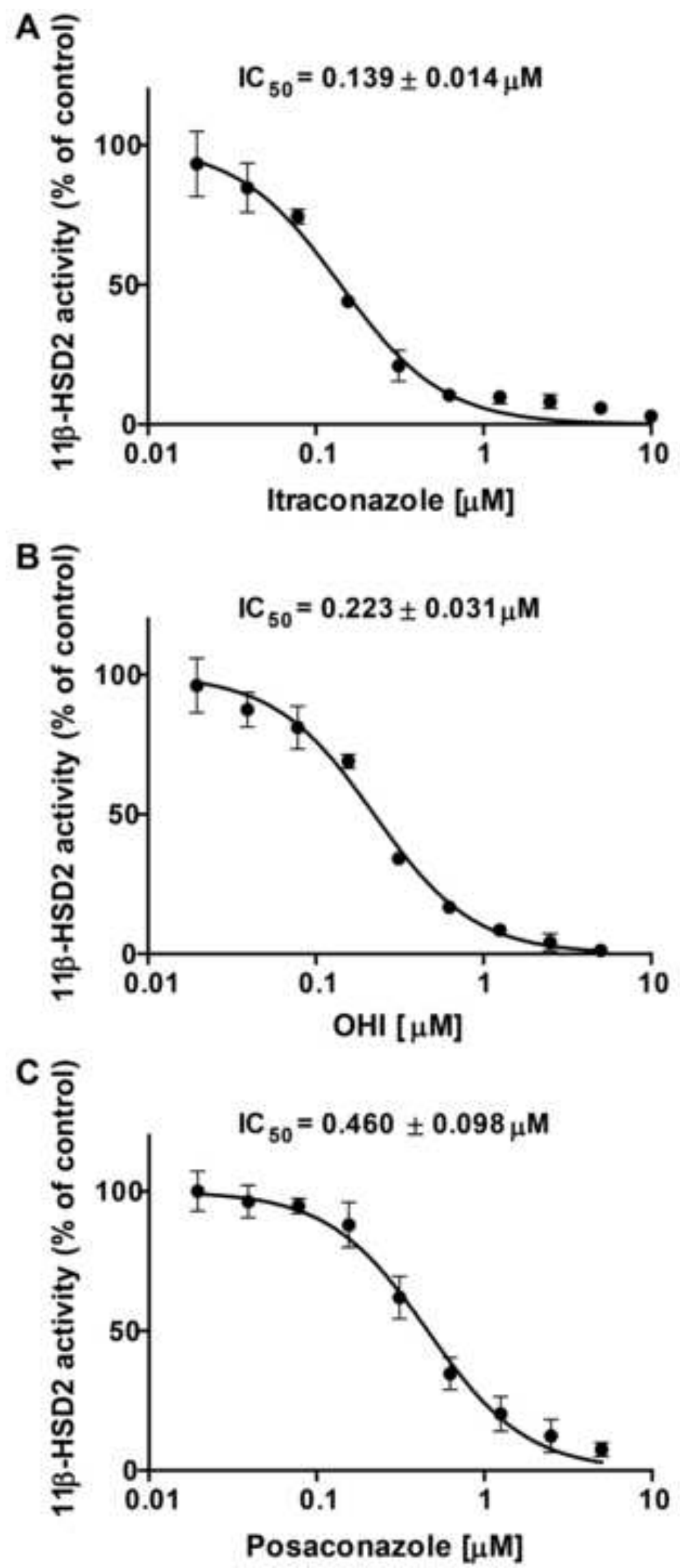
A

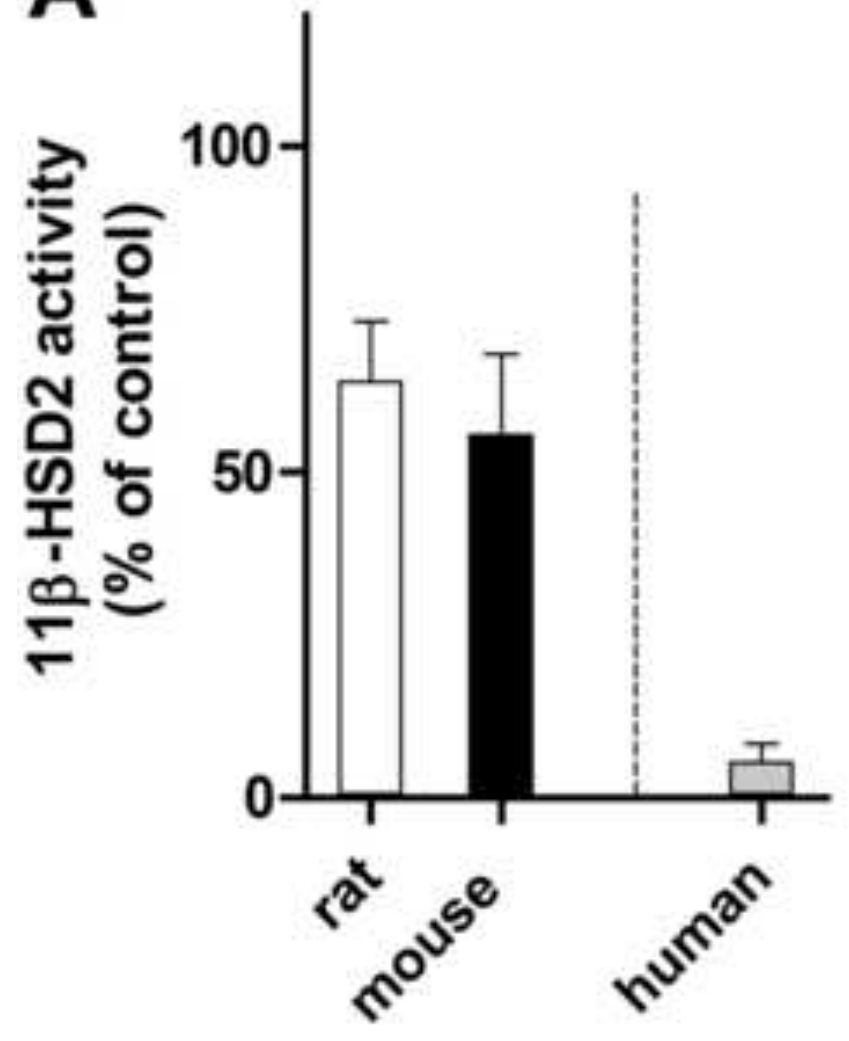

B

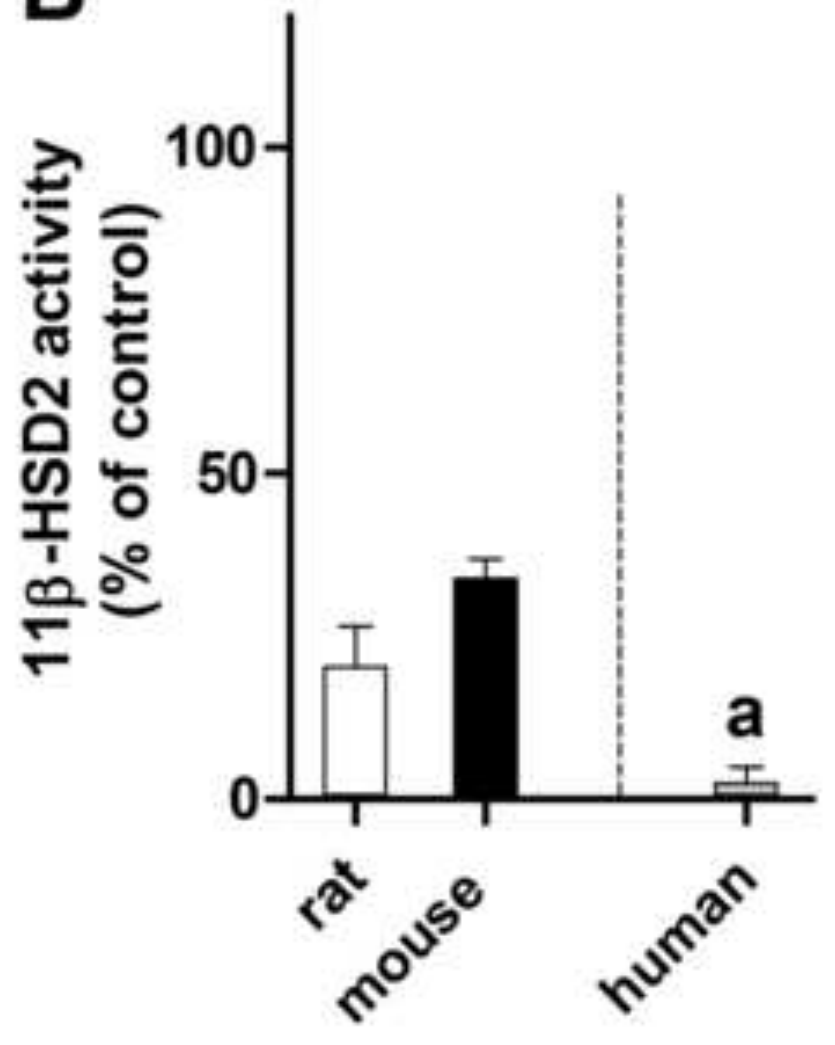

C

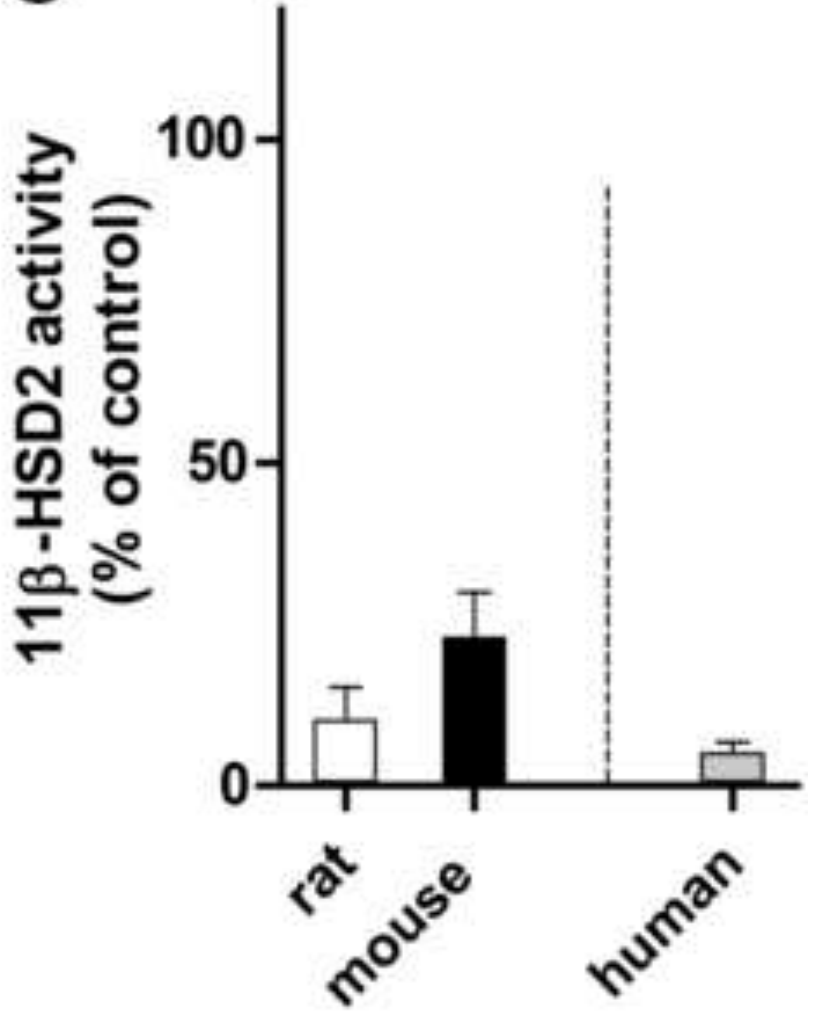


Figure5

Click here to download high resolution image

A
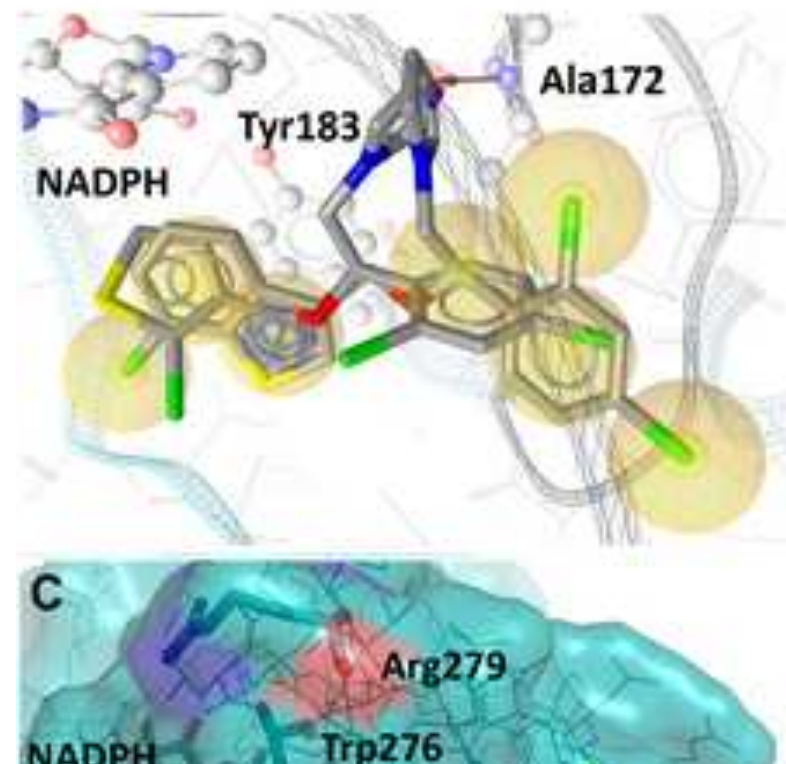

NADPH $=\operatorname{Trp276}$

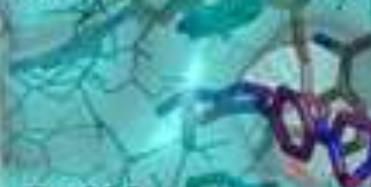

Tyr232

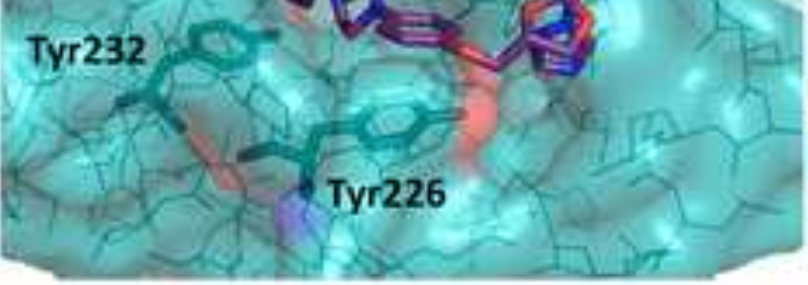

B
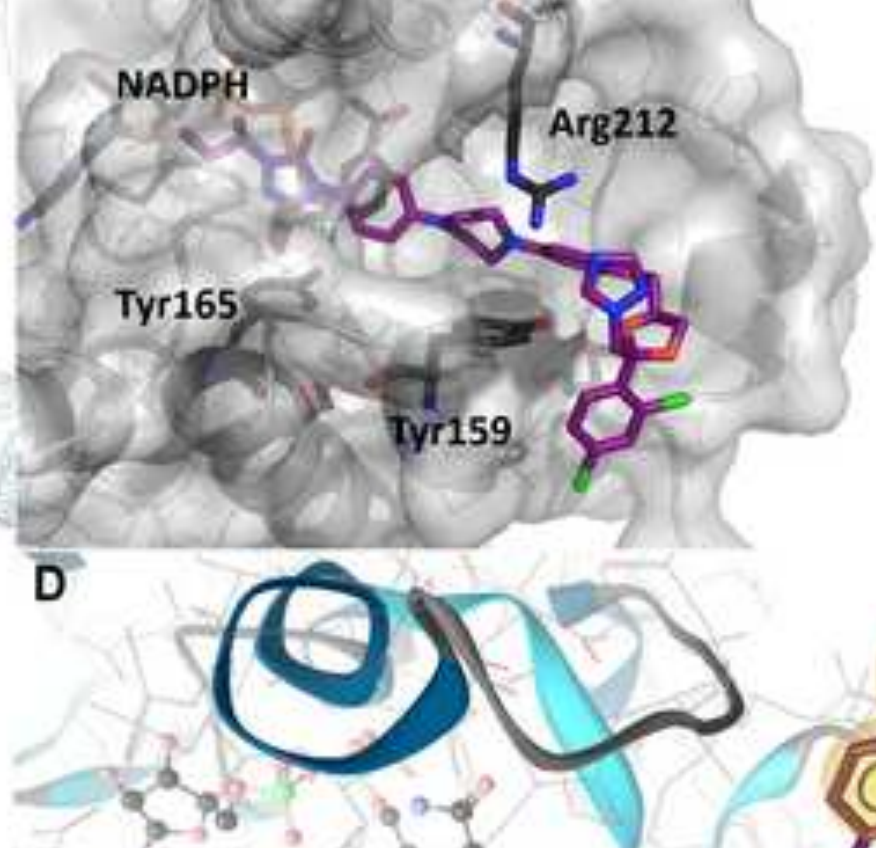

NADPH

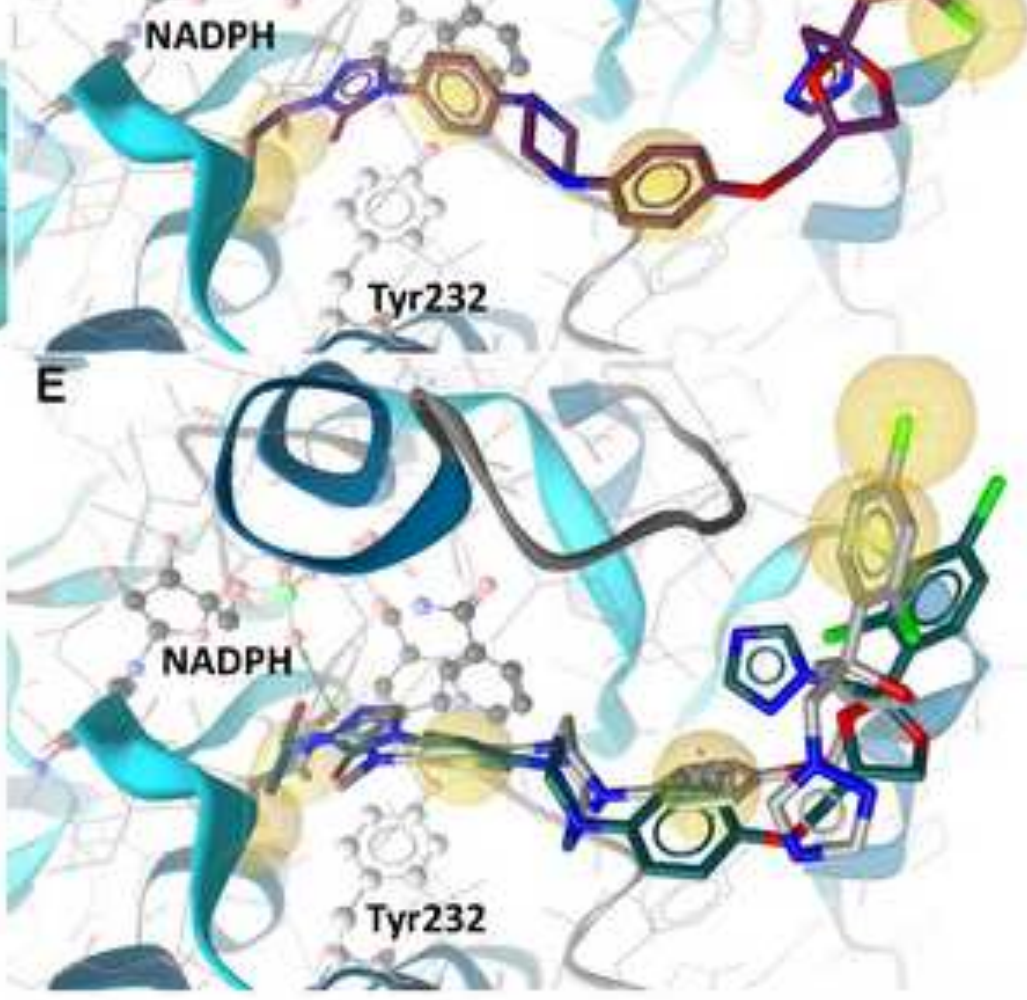




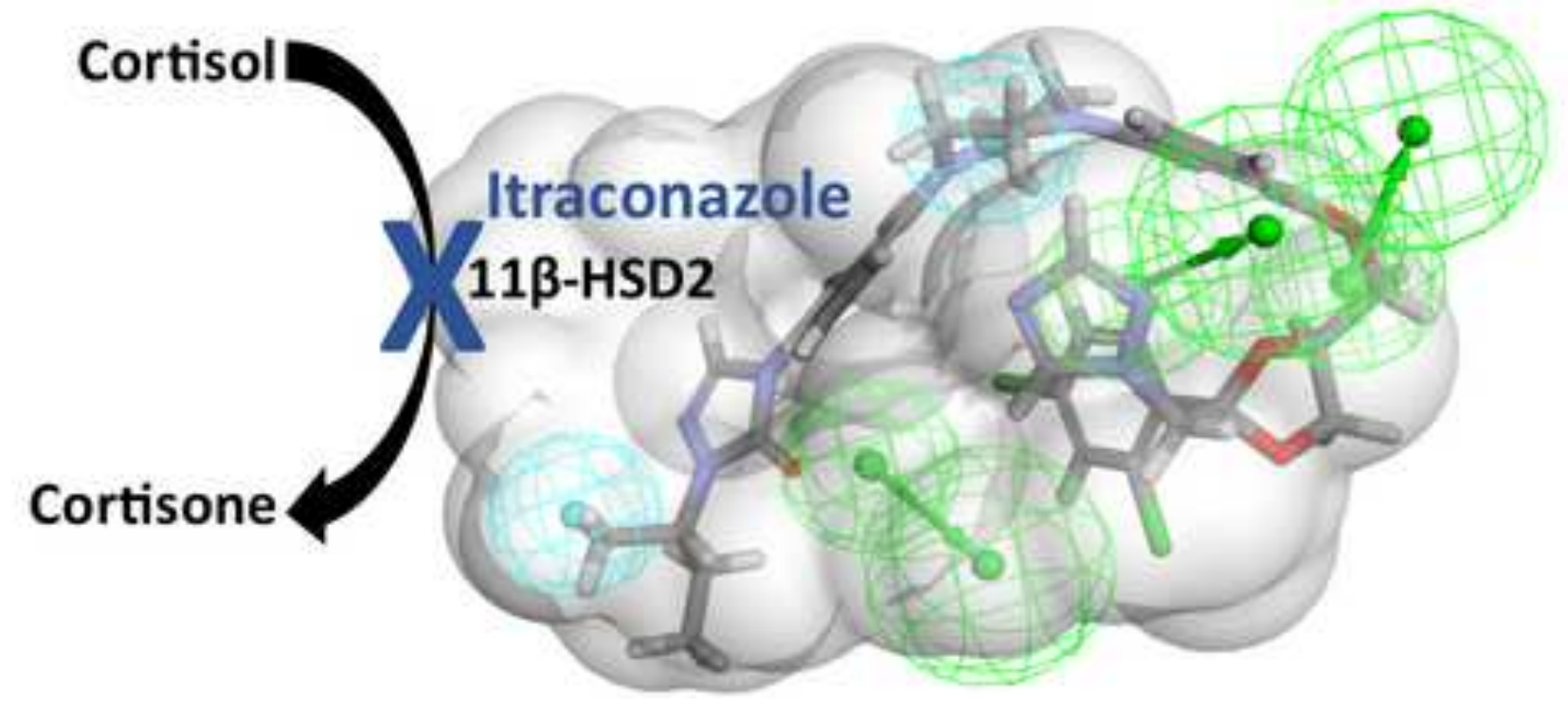

